\title{
Circadian clocks and insulin resistance
}

Citation for published version (APA):

Stenvers, D. J., Scheer, F. A. J. L., Schrauwen, P., la Fleur, S. E., \& Kalsbeek, A. (2019). Circadian clocks and insulin resistance. Nature Reviews Endocrinology, 15(2), 75-89. https://doi.org/10.1038/s41574-0180122-1

Document status and date:

Published: 01/02/2019

DOI:

10.1038/s41574-018-0122-1

Document Version:

Publisher's PDF, also known as Version of record

Document license:

Taverne

Please check the document version of this publication:

- A submitted manuscript is the version of the article upon submission and before peer-review. There can be important differences between the submitted version and the official published version of record.

People interested in the research are advised to contact the author for the final version of the publication, or visit the DOI to the publisher's website.

- The final author version and the galley proof are versions of the publication after peer review.

- The final published version features the final layout of the paper including the volume, issue and page numbers.

Link to publication

\footnotetext{
General rights rights.

- You may freely distribute the URL identifying the publication in the public portal. please follow below link for the End User Agreement:

www.umlib.nl/taverne-license

Take down policy

If you believe that this document breaches copyright please contact us at:

repository@maastrichtuniversity.nl

providing details and we will investigate your claim.
}

Copyright and moral rights for the publications made accessible in the public portal are retained by the authors and/or other copyright owners and it is a condition of accessing publications that users recognise and abide by the legal requirements associated with these

- Users may download and print one copy of any publication from the public portal for the purpose of private study or research.

- You may not further distribute the material or use it for any profit-making activity or commercial gain

If the publication is distributed under the terms of Article $25 \mathrm{fa}$ of the Dutch Copyright Act, indicated by the "Taverne" license above, 


\section{REVIEWS}

CIRCADIAN RHYTHMS IN ENDOCRINOLOGY AND METABOLISM

\section{Circadian clocks and insulin resistance}

Dirk Jan Stenvers (1) ', Frank A. J. L. Scheer ${ }^{2,3}$, Patrick Schrauwen ${ }^{4}$, Susanne E. Ia Fleur ${ }^{1,5,6}$ and Andries Kalsbeek $\mathbb{D}^{1,5,6 *}$

Abstract | Insulin resistance is a main determinant in the development of type 2 diabetes mellitus and a major cause of morbidity and mortality. The circadian timing system consists of a central brain clock in the hypothalamic suprachiasmatic nucleus and various peripheral tissue clocks. The circadian timing system is responsible for the coordination of many daily processes, including the daily rhythm in human glucose metabolism. The central clock regulates food intake, energy expenditure and whole-body insulin sensitivity, and these actions are further fine-tuned by local peripheral clocks. For instance, the peripheral clock in the gut regulates glucose absorption, peripheral clocks in muscle, adipose tissue and liver regulate local insulin sensitivity, and the peripheral clock in the pancreas regulates insulin secretion. Misalignment between different components of the circadian timing system and daily rhythms of sleep-wake behaviour or food intake as a result of genetic, environmental or behavioural factors might be an important contributor to the development of insulin resistance. Specifically, clock gene mutations, exposure to artificial light-dark cycles, disturbed sleep, shift work and social jet lag are factors that might contribute to circadian disruption. Here, we review the physiological links between circadian clocks, glucose metabolism and insulin sensitivity, and present current evidence for a relationship between circadian disruption and insulin resistance. We conclude by proposing several strategies that aim to use chronobiological knowledge to improve human metabolic health.

Insulin resistance in liver, muscle and adipose tissue is a pivotal pathophysiological process in the development of type 2 diabetes mellitus (T2DM), which has been designated as one of the four priority noncommunicable diseases by the $\mathrm{WHO}^{1}$. Major complications of T2DM are retinopathy, chronic kidney disease, neuropathy, peripheral vascular disease, myocardial infarction and stroke. The central approach in the prevention and treatment of insulin resistance is lifestyle modification. The second step is medication, with metformin being the cornerstone of the oral glucose-lowering drugs. If necessary, glycaemic control can be further improved with additional medication, including oral sulphonylureas, oral sodium-glucose cotransporter 2 (SGLT2) inhibitors, injectable glucagon-like peptide 1 (GLP1) receptor agonists or injectable insulin ${ }^{2}$. Traditionally, research has focused on the quantity and quality of physical activity, food intake and medication; however, circadian factors including the timing of light exposure, physical activity, food intake, medication and sleep-wake behaviour might also prove important for the prevention and treatment of insulin resistance.

The mammalian circadian timing system consists of a central brain clock in the hypothalamic suprachiasmatic nucleus (SCN), and peripheral clocks in other brain regions and tissues throughout the body, including muscle, adipose tissue and liver. The SCN receives a direct projection from the retina, via which environmental light synchronizes the approximately $24 \mathrm{~h}$ rhythm of the SCN with the exact $24 \mathrm{~h}$ rhythm of the environment (FIG. 1). The entrained timing signal from the SCN is forwarded via neural and hormonal signals and body temperature to the peripheral clocks. The molecular mechanism of the central and peripheral clocks is based on transcriptional-translational feedback loops, which are present in almost every cell of the human body.

In this Review, we describe the physiological links between circadian clocks, glucose metabolism and insulin sensitivity. We also present current evidence for the relationship between circadian disruption and insulin resistance, with a focus on human studies. Finally, we propose several strategies to implement chronobiological knowledge with the aim to improve human metabolic health. The chronobiology terms and metabolic terms we use are defined in BOX 1 and BOX 2, respectively.

\section{Circadian control of insulin sensitivity The circadian timing system}

The mammalian circadian timing system is composed of a central pacemaker in the bilateral SCN of the anterior hypothalamus and a multitude of peripheral clocks in other brain areas and peripheral tissues (FIG. 2). The 


\section{Key points}

- The circadian timing system consists of a central brain clock in the hypothalamic suprachiasmatic nucleus and peripheral clocks in tissues, including the liver, muscle, adipose tissue and pancreas.

- Misalignment between different components of the circadian timing system and daily rhythms of sleep-wake behaviour and food intake might contribute to the development of insulin resistance.

- Strategies to improve metabolic health by circadian synchrony include modulating light exposure, modulating rhythmic behaviour and chronotherapy.

- Circadian molecules are a promising new treatment option for insulin resistance.

\section{Period}

The time difference between two consecutive peaks or

troughs, or any other fixed point in the rhythm. In the case

of daily or circadian rhythms,

this period is exactly or

approximately $24 \mathrm{~h}$

respectively. The period of the

rhythm in constant conditions

is called the free-running

period and is denoted by the

Greek letter $\tau$ circadian timing system serves to prepare an organism for the alternating opportunities and challenges that go along with the rhythmic changes of the daily light-dark cycle. This concept is illustrated by the evolutionary advantage of an internal clock that matches the period duration of the environment, as demonstrated in cyanobacteria ${ }^{3,4}$.

The discovery of the molecular mechanism that keeps these clocks functioning was awarded the 2017 Nobel Prize in Physiology or Medicine. The central feature of this molecular mechanism is the transcriptionaltranslational feedback loop (TTFL) involving the core clock genes: the period genes (PER1, PER2 and PER3), cryptochrome genes (CRY1 and CRY2), ARNTL (also known as BMAL1), CLOCK (or its orthologue NPAS2) and the genes encoding the nuclear receptors REV-ERB (NR1D1 and NR1D2) and ROR (RORA, RORB and $R O R C)$. The rhythmic signal produced by this molecular clock has a period of approximately $24 \mathrm{~h}$, which is a circadian period.

The period of the endogenous circadian timing system does not match the exact $24 \mathrm{~h}$ rhythm of the outside world and, therefore, has to be reset every day. Environmental light is the most important Zeitgeber for resetting the central pacemaker, reaching the SCN through a direct connection from intrinsically photosensitive retinal ganglion cells through the retinohypothalamic tract. The remaining clocks in the circadian timing system therefore depend predominantly on the SCN for entrainment to the light-dark cycle of the outside world.

The SCN sends its entrained timing signal to the peripheral tissue clocks through the autonomic nervous system, hormonal signals (including melatonin and cortisol), modulation of body temperature, and behavioural signals, such as physical activity and food

\section{Author addresses}

${ }^{1}$ Department of Endocrinology and Metabolism, Amsterdam University Medical Centers, University of Amsterdam, Amsterdam, Netherlands.

2Division of Sleep Medicine, Harvard Medical School, Boston, MA, USA.

${ }^{3}$ Medical Chronobiology Program, Division of Sleep and Circadian Disorders, Brigham and Women's Hospital, Boston, MA, USA.

${ }^{4}$ Department of Nutrition and Movement Sciences, NUTRIM, School for Nutrition and Translational Research in Metabolism, Maastricht University Medical Center, Maastricht, Netherlands.

${ }^{5}$ Laboratory for Endocrinology, Department of Clinical Chemistry, Amsterdam University Medical Centers, University of Amsterdam, Amsterdam, Netherlands.

${ }^{6}$ Netherlands Institute for Neuroscience (NIN), Royal Dutch Academy of Arts and

Sciences (KNAW), Amsterdam, Netherlands.
}

intake. As most peripheral clocks do not receive direct light information, they are also sensitive to these other Zeitgebers. This scenario is especially true for peripheral clocks in metabolic tissues such as liver, white adipose tissue (WAT), brown adipose tissue (BAT), pancreas and muscle, which use the metabolic signals resulting from food intake for their entrainment ${ }^{5-8}$ (FIG. 1).

\section{Circadian rhythm in glucose metabolism}

In healthy humans, plasma glucose tolerance depends on the time of day of glucose ingestion, with glucose tolerance being higher in the morning than in the evening ${ }^{9,10}$. This diurnal rhythm in glucose tolerance is partly mediated by the diurnal rhythm in whole-body insulin sensitivity ${ }^{11}$. Moreover, the time-dependent glucose tolerance in healthy individuals is strongly mediated by the rhythm in pancreatic $\beta$-cell glucose sensitivity (that is, pancreatic glucose-induced insulin secretion), as demonstrated by studies that use hyperglycaemic clamping ${ }^{12}$ and a triple-tracer mixed-meal technique ${ }^{13}$. However, because participants in these studies were sleeping at night and were awake during the day, it remains unclear to what extent these morning-evening differences are the result of behavioural and environmental differences or are caused by a direct influence of the circadian system. A 2015 study using a circadian misalignment protocol demonstrated that the diurnal rhythm in glucose tolerance is robustly regulated by the circadian timing system, separate from influences of behavioural and environmental changes ${ }^{14}$. Consistent with the results from diurnal studies, the endogenous circadian influence on glucose tolerance results from a stronger $\beta$-cell response in the circadian morning ${ }^{14}$.

\section{Clock control of insulin sensitivity}

In this section, we discuss the clocks in the different tissues and organs that are involved in the control of glucose metabolism and explain their role in the regulation of insulin sensitivity and insulin secretion.

The central clock. The central clock in the SCN not only synchronizes the peripheral clocks described in the sections below, but also affects multiple processes that influence the diurnal rhythm in glucose metabolism, including the physiological daily rhythms in sleepwake behaviour, food intake, hormone secretion, insulin sensitivity and energy expenditure (FIG. 3).

The SCN controls the daily rhythm in sleep-wake behaviour ${ }^{15,16}$ via its connections with hypothalamic areas such as the subparaventricular zone, the ventrolateral preoptic area and the dorsomedial hypothalamus ${ }^{17}$. The SCN presumably also has a direct role in the control of food intake $e^{18,19}$, which is enhanced via the regulation of the sleep-wake cycle since food intake requires a waking state. The circadian control of food intake might be mediated via direct neuroanatomical connections between the SCN and the hypothalamic arcuate nucleus, which is involved in the regulation of food intake ${ }^{20}$, but indirect connections between the SCN and areas involved in the rewarding aspects of food could also have a role ${ }^{21}$.

In addition to the aforementioned roles, the SCN controls the daily rhythm of release of several hormones 
affecting glucose tolerance. Firstly, the activity of the hypothalamic-pituitary-adrenal axis is regulated via connections from the SCN to the paraventricular nucleus, resulting in a diurnal rhythm of cortisol

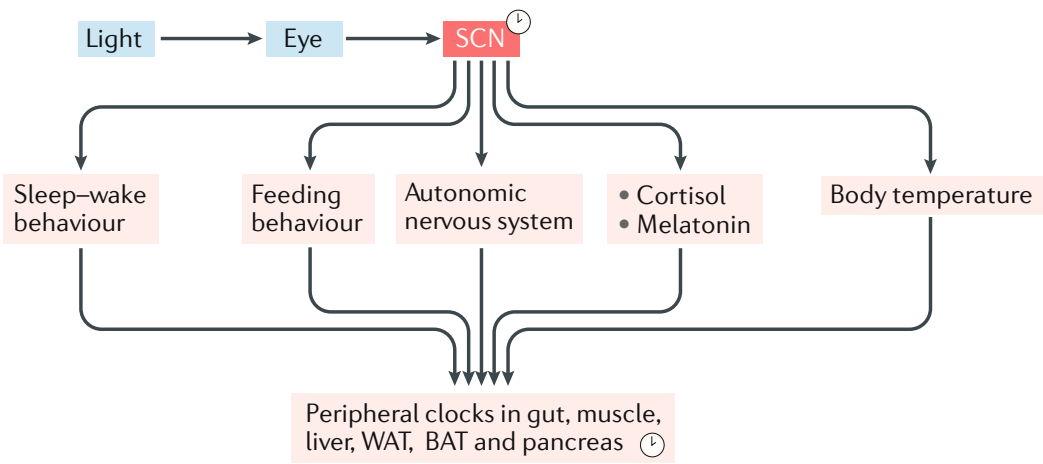

Fig. 1 | The circadian timing system. The circadian timing system is composed of a central clock in the suprachiasmatic nucleus (SCN) located in the hypothalamus of the brain and peripheral clocks in other brain areas and peripheral tissues. The circadian rhythms in these clocks are generated by a molecular transcriptionaltranslational feedback loop. The light signal, reaching the SCN via the retina and the retinohypothalamic tract, is the most important Zeitgeber for the SCN. The SCN synchronizes peripheral clocks through neural, endocrine, temperature and behavioural signals. BAT, brown adipose tissue; WAT, white adipose tissue.

\section{Box 1 Concepts in circadian studies}

\section{Chronobiology}

The study of biological rhythms such as daily, tidal, weekly, monthly and seasonal rhythms.

\section{Chronotype}

Humans can be characterized according to their preferred sleep times; late chronotypes (owls) prefer to sleep later than early chronotypes (larks).

\section{Circadian rhythm}

A rhythm with a period of $\sim 24 \mathrm{~h}$ that persists in constant conditions. Circadian comes from the Latin words circa, which means around, and dies, which means one day.

\section{Daily (diurnal) rhythm}

Physiological, hormonal and behavioural rhythms that are measured under regular light-dark and sleep-wake cycles, and therefore should be described as daily rhythms, instead of circadian rhythms.

\section{Entrainment and Zeitgeber}

The non-24 $\mathrm{h}$ period of the endogenous circadian rhythm can be adjusted, aligned or synchronized to the exact $24 \mathrm{~h}$ period of the outside world by a process called entrainment. The external stimulus responsible for this entrainment is called a Zeitgeber. In mammals the strongest Zeitgeber for the endogenous central brain clock is environmental light, but food intake, locomotor activity and temperature can also serve as Zeitgebers.

\section{Nocturnal species}

Species that are mainly awake and active during the dark period, such as most rodents.

Diurnal species

Species that are mostly awake and active during the light period, such as humans.

\section{Chronotherapy}

The specific timing of administration of drug classes based on the diurnal rhythms in pharmacodynamics and pharmacokinetics of therapeutic drugs.

\section{Suprachiasmatic nucleus lesion}

In rodents, a thermal or electrolytic complete lesion of the suprachiasmatic nucleus neurons causes a loss of all circadian rhythmicity (that is, the absence of daily rhythms in locomotor activity and food intake, but also in hormone release, body temperature and metabolic fluxes).

\section{Misalignment protocol}

An experimental protocol using a recurring non-24h behavioural cycle (for example, a $28 \mathrm{~h}$ cycle). This protocol can be used to investigate the relative contributions of the endogenous circadian cycle and the behavioural cycle to a particular physiological rhythm. secretion, with a peak before the onset of the active period $^{22}$. The glucocorticoid cortisol affects insulin signalling and reduces insulin secretion ${ }^{23}$. Secondly, the circadian rhythm of melatonin (also known as the hormone of darkness, as it is exclusively released during the dark phase in diurnal and nocturnal species alike), which affects insulin secretion ${ }^{24,25}$, is orchestrated by output from the SCN, via the paraventricular nucleus and the intermediolateral column to the pineal gland $^{26}$. Thirdly, the diurnal rhythm in growth hormone, which antagonizes insulin action in liver and muscle ${ }^{27}$, is partly regulated by the SCN via its control of the sleep-wake cycle ${ }^{27-29}$.

Furthermore, SCN lesion studies in rodents demonstrated that the SCN controls the diurnal rhythm in whole-body insulin sensitivity ${ }^{30}$ and reported that within 8 weeks of an SCN lesion being created, rodents are insulin resistant ${ }^{31}$. In humans, a role for the SCN in the control of insulin sensitivity is suggested by misalignment protocols demonstrating the endogenous circadian control of glucose tolerance, independent of behavioural rhythms $\mathrm{s}^{14,32}$.

Finally, the central clock is responsible for the circadian regulation of multiple components of energy expenditure, such as the sleep-wake cycle ${ }^{15,16}$, dietinduced thermogenesi ${ }^{33}$, resting energy expenditure ${ }^{34}$ and (at least in rodents) BAT activity ${ }^{35-37}$.

The gut clock. Glucose enters the body via the gastrointestinal tract. Intestinal cells throughout the intestinal tract contain a molecular clock ${ }^{38,39}$ and this gut clock is synchronized by signals resulting from food intake ${ }^{38}$. The gut clock regulates intestinal motility ${ }^{40}$ and nutrient absorption (FIG. 4). ARNTL regulates the expression of membrane glucose transporters and thus matches the timing of maximal monosaccharide uptake to the habitual feeding period ${ }^{41}$. Brush border disaccharidases, including sucrase, display a circadian rhythm in activity ${ }^{42,43}$, but the mechanism regulating this circadian activity remains to be elucidated (FIC. 4).

The muscle clock. Human skeletal muscle has an autonomous molecular clock ${ }^{44,45}$ (FIG. 5). Rodent data showed that the SCN synchronizes the skeletal muscle clock $^{46,47}$, but signals resulting from physical exercise ${ }^{48,49}$ and food intake have also been shown to be involved in synchronization ${ }^{49-51}$.

Cultured rodent myotubes express circadian rhythmicity in insulin sensitivity ${ }^{52}$. CLOCK and ARNTL regulate muscle insulin sensitivity via changes in protein levels and membrane translocation of the insulinsensitive glucose transporter GLUT4 (REF. ${ }^{53}$ ), as well as through the modulation of the insulin signalling pathway via expression of the deacetylase SIRT1 (REF. ${ }^{54}$ ). Furthermore, a 2017 study showed that the muscle clock regulates muscle insulin sensitivity via histone deacetylation of metabolic genes by HDAC3 (REF. ${ }^{55}$ ) (FIC. 5). Consistently, human muscle tissue shows a diurnal rhythm in insulin sensitivity with higher insulin sensitivity in the morning than in the evening ${ }^{56}$, as well as a diurnal rhythm in mitochondrial oxidative capacity, which peaks in the evening ${ }^{57}$. 


\section{Box 2 | Metabolic definitions}

\section{Insulin resistance ${ }^{240}$}

Resistance to the physiological effects of insulin at the tissue level. The gold standard to measure insulin sensitivity is the hyperinsulinaemic euglycaemic clamp.

HOMA-IR ${ }^{241}$

Homeostatic model assessment of insulin resistance, based on a single combination of fasting glucose and insulin levels.

\section{Glucose tolerance}

Plasma glucose excursion after a fixed oral or intravenous glucose load, with higher glucose excursions being indicative of reduced glucose tolerance.

\section{Prediabetes}

Fasting plasma glucose $5.6-6.9 \mathrm{mmol} / \mathrm{l}(100-125 \mathrm{mg} / \mathrm{dl}), 2 \mathrm{~h}$ plasma glucose after oral glucose tolerance test $(75 \mathrm{~g}$ glucose $) 7.8-11.0 \mathrm{mmol} / \mathrm{l}(140-199 \mathrm{mg} / \mathrm{dl})$ or $\mathrm{HbA}_{1 \mathrm{c}}$ $39-47 \mathrm{mmol} / \mathrm{mol}(5.7-6.4 \%)$.

\section{Diabetes mellitus ${ }^{2}$}

Fasting plasma glucose $\geq 7 \mathrm{mmol} / \mathrm{l}$ ( $126 \mathrm{mg} / \mathrm{dl})$, $2 \mathrm{~h}$ plasma glucose after oral glucose tolerance test $(75 \mathrm{~g}$ glucose $) \geq 11.1 \mathrm{mmol} / \mathrm{l}(200 \mathrm{mg} / \mathrm{dl})$ or $\mathrm{HbA}_{1 \mathrm{c}} \geq 48 \mathrm{mmol} / \mathrm{mol}(\geq 6.5 \%)$ or random plasma glucose $\geq 11.1 \mathrm{mmol} / \mathrm{l}(200 \mathrm{mg} / \mathrm{dl})$ with hyperglycaemic symptoms.

\section{Type 2 diabetes mellitus}

Diabetes mellitus due to peripheral insulin resistance, combined with relative insulin deficiency.

The metabolic syndrome ${ }^{242}$

Three or more of the following:

- Waist circumference $>102 \mathrm{~cm}$ in men or $>88 \mathrm{~cm}$ in women

- Triglycerides $\geq 1.69 \mathrm{mmol} / \mathrm{l}(150 \mathrm{mg} / \mathrm{dl})$

- HDL-cholesterol $<1.04 \mathrm{mmol} / \mathrm{l}(40 \mathrm{mg} / \mathrm{dl})$ in men or $<1.30 \mathrm{mmol} / \mathrm{l}(50 \mathrm{mg} / \mathrm{dl})$ in women

- Blood pressure $\geq 130 / 85 \mathrm{mmHg}$

- Fasting plasma glucose $\geq 5.6 \mathrm{mmol} / \mathrm{l}(100 \mathrm{mg} / \mathrm{dl})$

The adipose tissue clock. WAT contains an autonomous circadian clock as shown in both rodent ${ }^{58,59}$ and human ${ }^{60,61}$ in vitro models (FIG. 6). Similar to the muscle clock, the WAT clock is synchronized by the $\mathrm{SCN}^{62}$ and by signals resulting from food intake ${ }^{63,64}$.

Adipocytes from rodents have circadian rhythmicity in glucose uptake ${ }^{52}$. In line with this observation, in human WAT $\sim 25 \%$ of the transcriptome shows diurnal variation, including pathways involved in the regulation of glucose uptake ${ }^{65}$. Subcutaneous WAT explants from humans who are obese show an intrinsic diurnal rhythm in insulin signalling as determined by AKT phosphorylation, with peak insulin sensitivity at noon ${ }^{66}$. Rodent data indicated that this diurnal rhythm in adipose tissue insulin sensitivity could be the result of circadian regulation of the retinol-binding protein receptor STRA6 $\left(\mathrm{REF}^{67}\right)$. In addition, CLOCK and ARNTL regulate the expression of key enzymes in the regulation of lipolysis such as adipose triglyceride lipase (ATGL), lipoprotein lipase (LPL) and hormone-sensitive lipase (HSL) ${ }^{68,69}$ (FIG. 6).

BAT from mice also shows a diurnal rhythm in glucose uptake . A $^{70} 2016$ human study confirmed circadian rhythmicity of glucose uptake in BAT, with peak activity just before waking up ${ }^{71}$.

The liver clock. The liver contains an autonomous clock that is synchronized by the $\mathrm{SCN}^{72,73}$ via a combination of autonomic signals and endocrine signals ${ }^{64}$ (FIG. 7). The liver clock also responds strongly to the timing of food intake, as the liver clock can be uncoupled from the SCN clock by inverting the daily feeding rhythm ${ }^{74}$. The liver clock regulates several pathways involved in the control of glucose and lipid metabolism, as indicated by microarray ${ }^{73,75,76}$, proteomic ${ }^{77,78}$ and metabolomic ${ }^{79-81}$ studies.

By synchronizing the diurnal rhythms in gluconeogenesis and glucose export to the habitual fasting period, the liver clock in rodents is essential to maintain euglycaemia ${ }^{82,83}$. The repression of gluconeogenesis during the feeding period is mediated by the interaction of CRY (which has its diurnal peak of expression during the feeding period) with the glucocorticoid receptor ${ }^{84}$ and with $G$ protein-coupled receptor signalling ${ }^{85}$. The overall result of these interactions is the repression of the expression of rate-limiting gluconeogenetic genes. In addition, insulin-mediated suppression of gluconeogenesis is partly dependent upon CRY-mediated FOXO1 degradation $^{86,87}$ (FIG. 7). In view of this information, it is tempting to speculate that the liver clock contributes to the diurnal rhythms in hepatic glycogen content ${ }^{88}$ and in hepatic insulin sensitivity ${ }^{13}$ that are observed in healthy individuals.

In addition to the regulation of gluconeogenesis, the liver clock regulates the diurnal rhythm in mitochondrial dynamics (FIG. 7). Therefore, the liver clock is involved in regulating mitochondrial glucose oxidation and fatty acid oxidation ${ }^{89,90}$, which protects the liver against oxidative stress during fasting ${ }^{91}$.

The pancreatic clock. The presence of an autonomous circadian pancreatic clock $^{92}$ has been demonstrated not only in rodents ${ }^{93-95}$, but also in human islets and dispersed human islet cells (that is, the cells were cultured as seperate or single cells, not as an intact islet) ${ }^{96,97}$. The pancreatic clock is synchronized to the light-dark cycle ${ }^{95}$ via signals derived from the central brain clock in the SCN that include autonomic neuronal signals ${ }^{98}$, melatonin release ${ }^{93}$, glucocorticoid release ${ }^{96}$ and changes in body temperature ${ }^{96}$. The amplitude of oscillations in the expression of clock genes in cultured rat islets is dependent on the glucose concentration in the culture medium $^{95}$.

Pancreatic islets isolated from rats show a circadian rhythm in insulin secretion ${ }^{93}$. CLOCK and BMAL1 activate the transcription of genes involved in insulin biosynthesis, insulin transport and glucose-stimulated insulin secretion ${ }^{99}$ (FIG. 8). In line with this observation, disruption of the pancreatic clock causes defective insulin secretion ${ }^{94,100,101}$. Similarly, in human pancreatic islets one group has confirmed that the pancreatic clock controls insulin secretion ${ }^{97}$.

\section{Circadian disruption \\ Insulin resistance}

Insulin resistance of liver, muscle and adipose tissue, which is initially compensated for by increased insulin secretion, is an early characteristic in the development of T2DM. Of note, in addition to insulin resistance, $\beta$-cell failure contributes to the development of $\mathrm{T} 2 \mathrm{DM}^{102}$.

Insulin resistance in skeletal muscle is characterized by a reduced insulin-stimulated glucose uptake as a result of reduced insulin signalling and GLUT4 translocation $^{103}$. As skeletal muscle is responsible for the 


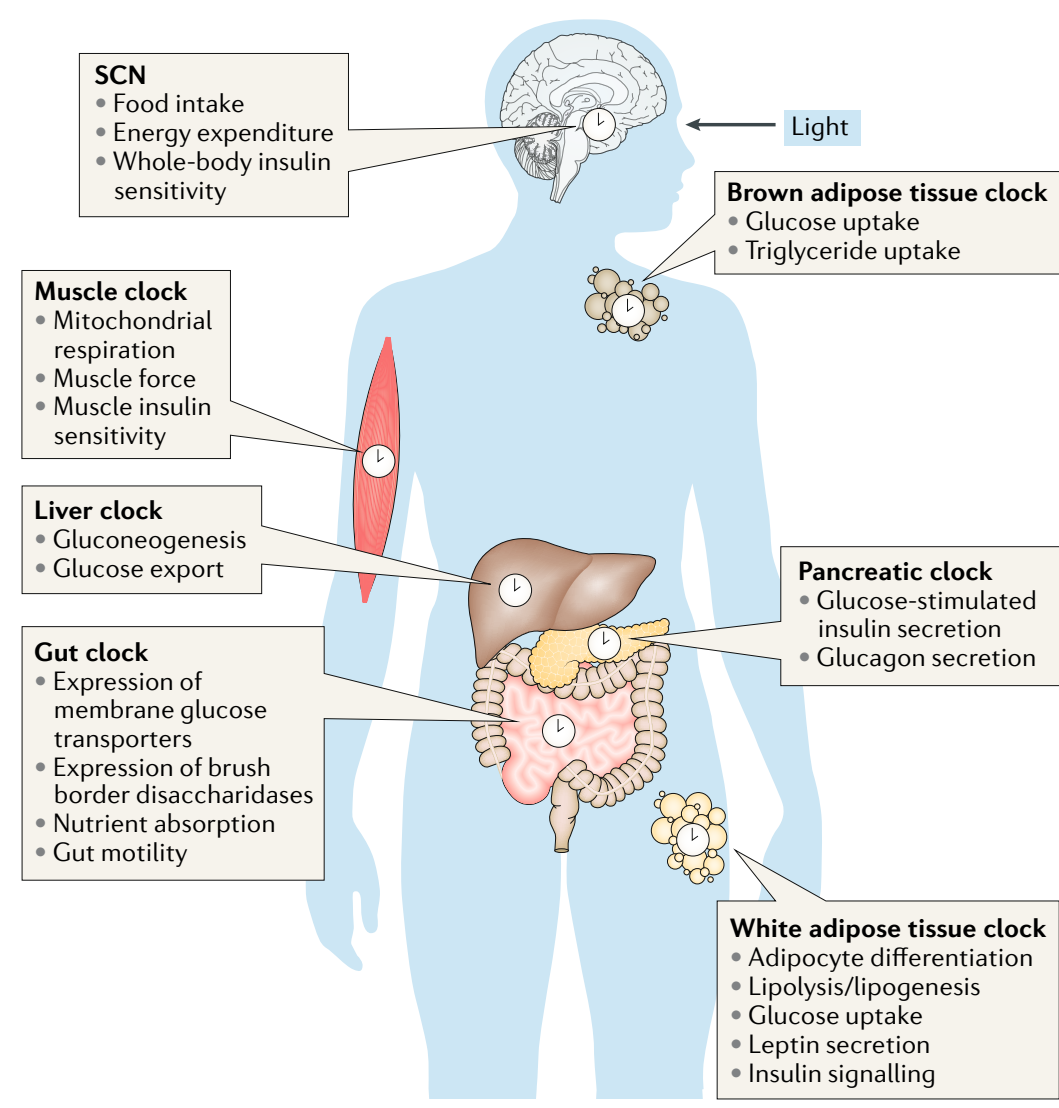

Fig. 2 | Circadian clocks regulate glucose metabolism, insulin sensitivity and insulin secretion. The molecular clock consists of a transcriptional translational feedback loop involving the clock proteins CLOCK, ARNTL, PER and CRY and the nuclear receptors NR1D1, NR1D2 and ROR. The central and peripheral clocks are responsible for a variety of functions. SCN, suprachiasmatic nucleus.

Amplitude

On a line graph, the amplitude is half the distance between the peak and trough of a daily or circadian rhythm. majority of glucose uptake in the postprandial state ${ }^{104}$, skeletal muscle insulin resistance contributes to elevated postprandial glucose levels and reduced glucose tolerance.

The main role of the liver in the maintenance of glucose homeostasis is to release glucose - that is, endogenous glucose production - when plasma glucose and insulin levels are low. Under normal conditions, endogenous glucose production is strongly suppressed by insulin. Following hepatic insulin resistance, endogenous glucose production remains unsuppressed despite high plasma insulin levels, thereby contributing to elevated glucose levels via enhanced gluconeogenesis and reduced glucose uptake ${ }^{105}$. Insulin also suppresses de novo lipogenesis and VLDL production in the liver, and therefore hepatic insulin resistance is also characterized by elevated VLDL secretion ${ }^{106}$.

The role of adipose tissue insulin resistance in the development of T2DM is more indirect than that of muscle and hepatic insulin resistance. Insulin suppresses adipose tissue lipolysis; therefore, patients with T2DM are characterized by having elevated levels of plasma free fatty acids ${ }^{107}$. Tissues such as liver and muscle take up the additional circulating plasma free fatty acids, which contributes to ectopic lipid accumulation. This ectopic fat accumulation in itself strongly contributes to the development of liver and muscle insulin resistance ${ }^{108}$.

\section{Circadian disruption and insulin resistance}

The first clue that the circadian timing system might be involved in the pathophysiology of insulin resistance was the observation in the 1960s of an altered daily rhythm in glucose tolerance in patients with $\mathrm{T}_{2} \mathrm{DM}^{109}$. Later, observations including the development of metabolic syndrome in the Clock mutant mouse ${ }^{110}$, the discovery that food intake at the wrong circadian phase (the habitual sleeping phase) causes obesity in mice ${ }^{111}$ and the observation that circadian misalignment results in decreased glucose tolerance in humans ${ }^{112}$ led to the proposal of the circadian disruption hypothesis ${ }^{113}$. Sophisticated tissue-specific pancreatic $^{94,99,100,114}$, hepatic ${ }^{82,91}$, muscle $^{53,115}$ and adipose ${ }^{116}$ transgenic and knockout models gave further support for this hypothesis. On the other hand, several studies, including transgenic mouse models ${ }^{117-119}$ and studies with desynchronized food intake ${ }^{120-122}$, have not been able to confirm the circadian disruption hypothesis, as they reported no negative metabolic effects of circadian disruption. An overview of the metabolic phenotypes of published transgenic animal models is outside the scope of the present Review, but can be found in several previous papers ${ }^{123-125}$.

According to the circadian disruption hypothesis, metabolic health is optimal when the different daily rhythms, including the behavioural fasting-feeding and sleep-wake rhythms, hormonal and autonomic nervous system rhythms and central and peripheral clock rhythms, oscillate in synchrony with each other. By contrast, misalignment between certain components of this system, such as between behavioural and tissue clock rhythms, can result in circadian disruption and the development of insulin resistance and T2DM. In the sections below, we discuss epidemiological and experimental human studies that investigated the association between insulin resistance and several forms of circadian disruption (BOX 3).

Clock genes in humans. In line with the rodent clock gene mutation studies, human mutations in several clock genes were shown to contribute to the genetic susceptibility to obesity, insulin resistance and T2DM. Observational studies have shown associations between single nucleotide polymorphisms in $A R N T L^{126}$ and T2DM, between specific haplotypes of CLOCK and obesity $^{127,128}$, between polymorphisms in CRY2 and elevated fasting glucose $\mathrm{e}^{129,130}$ and between polymorphisms in the circadian clock gene NR1D1 and obesity ${ }^{131}$. Inspired by these findings, several investigators explored genebehaviour interactions and showed that interactions between diet and clock gene mutations affect fasting glucose $^{132}$, insulin resistance ${ }^{133,134}$, body weight ${ }^{135,136}$ and $\mathrm{T} 2 \mathrm{DM}^{137}$.

We only identified three studies that investigated tissue clock gene expression rhythms in patients with T2DM. One study described a reduced amplitude of the daily rhythm in leukocyte clock gene expression in patients with $\mathrm{T} 2 \mathrm{DM}^{138}$. Another study investigated the diurnal rhythm in clock gene expression in gluteal subcutaneous adipose tissue and surprisingly found no differences between lean participants, participants 


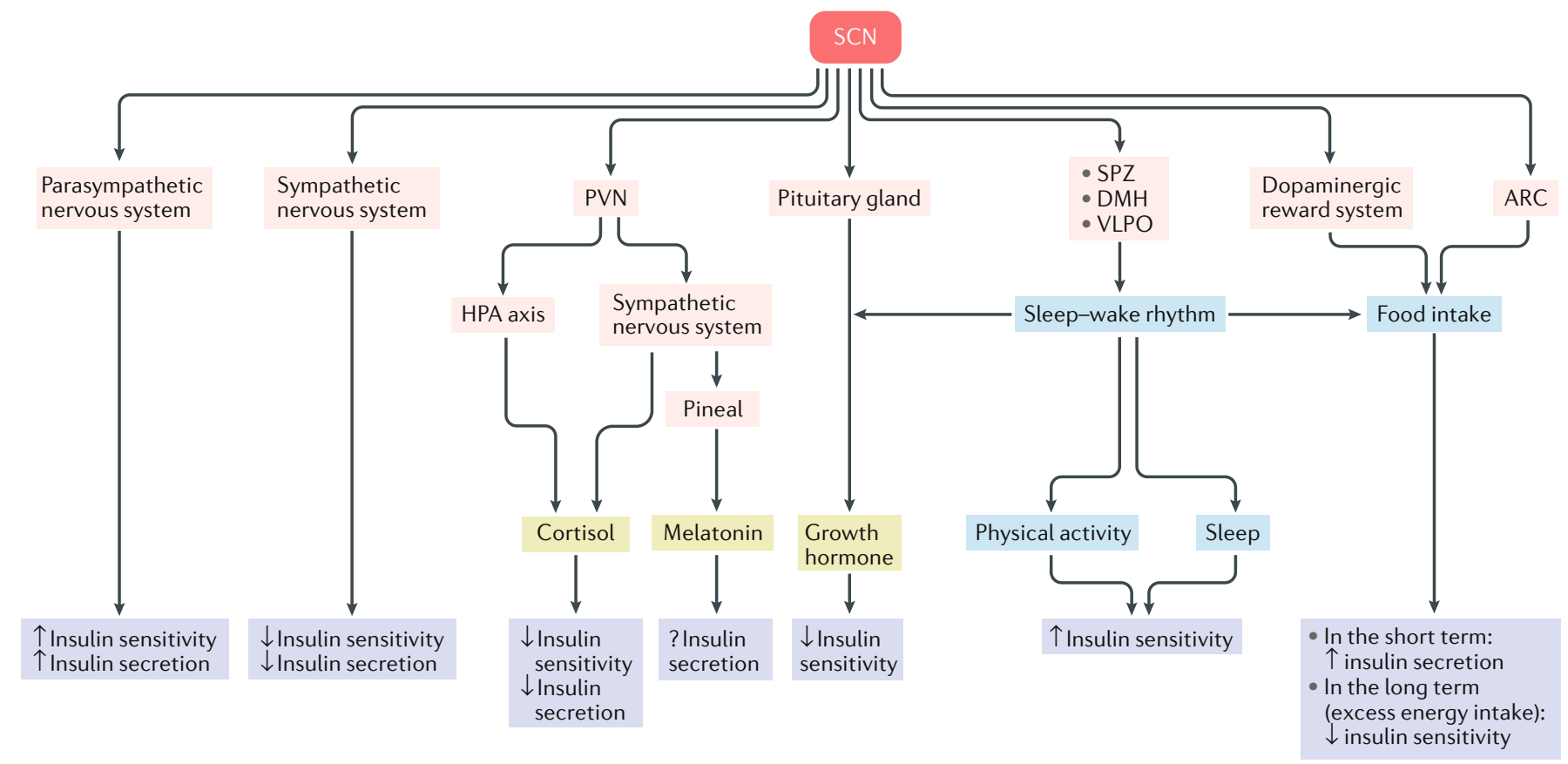

Fig. 3 | The central clock. The suprachiasmatic nucleus (SCN), which contains the central clock, controls the daily rhythms of sleep-wake behaviour and food intake via hypothalamic connections. The central clock controls the circadian rhythm in the secretion of hormones affecting glucose tolerance, including cortisol, melatonin and growth hormone. ARC, arcuate nucleus; DMH, dorsomedial hypothalamus; HPA axis, hypothalamus-pituitary-adrenal axis; PVN, paraventricular nucleus; SPZ, subparaventricular zone; VLPO, ventrolateral preoptic nucleus.

with obesity and patients with $\mathrm{T}_{2} \mathrm{DM}^{139}$. A study in circadian myotube explants described unaltered clock gene expression rhythms, but a decreased amplitude in NR1D1 expression in patients with $\mathrm{T}_{2} \mathrm{DM}^{44}$. In sum, indications of altered tissue clock rhythms in patients with T2DM are very limited.

Effects of light. Daylight is the main synchronizer of the central clock. Our modern lifestyle, however, is characterized by reduced light exposure during the day and increased light exposure during the night. These lifestyle changes have a substantial effect on the alignment of our circadian timing system to the solar day, as illustrated by an elegant study that investigated the effects of camping in natural light-dark conditions on human daily sleep-wake behaviour ${ }^{140}$.

In several animal models, investigators have shown that dim light at night disturbs diurnal rhythms of food intake and locomotor behaviour ${ }^{120,125,141}$, causing obesity and reduced glucose tolerance in mice ${ }^{125,141}$ but not in rats $^{120}$. In line with these findings, observational studies in humans have shown correlations of exposure to light at night with obesity ${ }^{142,143}$ and $\mathrm{T}_{2} \mathrm{DM}^{144}$.

Under conditions of controlled food intake and physical activity, bright ambient light directly reduces insulin sensitivity in a time-dependent manner in healthy individuals ${ }^{145}$. When healthy participants are kept awake during the night, bright light causes increased levels of glucose in plasma ${ }^{146}$. In patients with T2DM, bright morning light increases fasting and postprandial levels of glucose $\mathrm{e}^{147}$. A 2017 study in rats reported wavelength-dependent effects of ambient light on glucose tolerance, with white and green light but not blue and red light reducing glucose tolerance ${ }^{148}$, but whether these observations translate to humans remains to be determined.

Melatonin. Melatonin is secreted by the pineal gland and shows a pronounced diurnal rhythm. During the dark period, plasma levels of melatonin are high ${ }^{149}$, and melatonin secretion is acutely suppressed by light exposure $^{26}$. Melatonin acutely increases insulin secretion in cultured human islets ${ }^{24}$. By contrast, melatonin administration in healthy women acutely decreases glucose tolerance ${ }^{150,151}$, an effect that is dependent on a common gain-of-function variant of the melatonin receptor gene MTNR1B ${ }^{152}$.

The role of melatonin signalling in the pathophysiology of T2DM remains a topic of lively debate ${ }^{153}$. On the one hand an association exists between reduced melatonin levels and the incidence of $\mathrm{T} 2 \mathrm{DM}^{154}$, and rare loss-of-function mutations in MTNR1B are associated with an increase in the risk of $\mathrm{T}_{2} \mathrm{DM}^{155}$. On the other hand, one publication suggests that increased pancreatic $\beta$-cell melatonin signalling might reduce insulin secretion in humans ${ }^{25}$.

Sleep-wake rhythms. Accumulating evidence from both epidemiological and experimental studies shows that behavioural sleep-wake rhythms affect the risk of developing insulin resistance. A 2015 meta-analysis of prospective studies showed that both individuals who sleep for short periods and those who sleep for long periods are at increased risk of developing T2DM, 


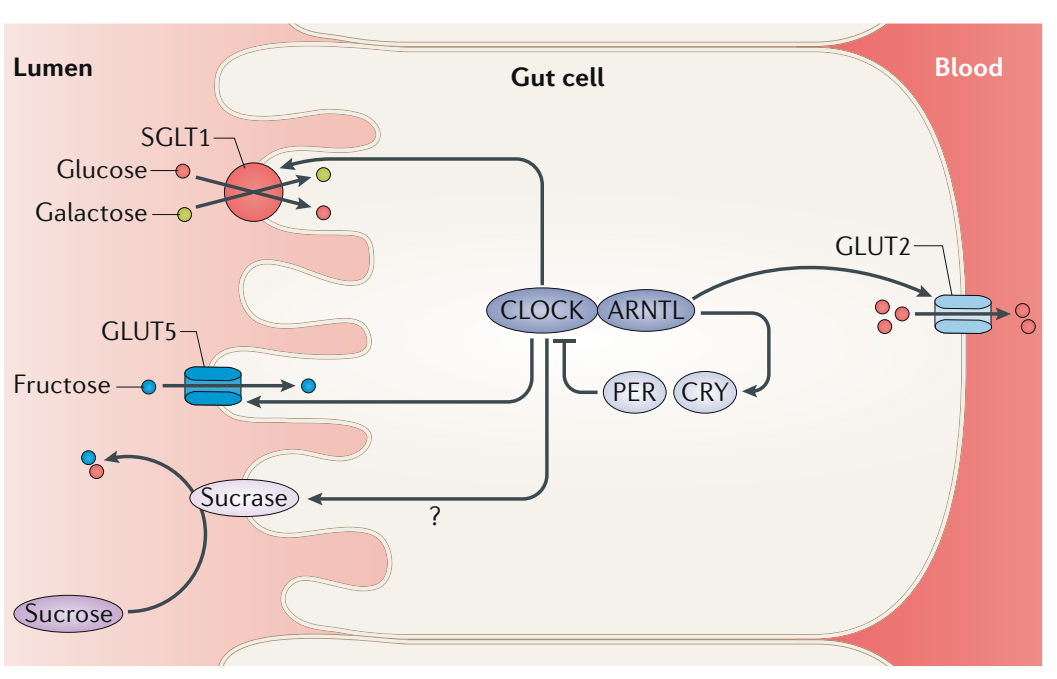

Fig. 4 | The gut clock. The molecular clock consists of a transcriptional-translational feedback loop involving the clock proteins CLOCK, ARNTL, PER and CRY and the nuclear receptors NR1D1, NR1D2 and ROR. The gut clock regulates the expression of membrane glucose transporters and brush border disaccharidases. GLUT, glucose transporter; SGLT1, sodium-glucose cotransporter 1.

with a proposed 'optimal' sleep duration of $7-8 \mathrm{~h}$ per night ${ }^{156}$.

The interpretation of epidemiological studies, however, should be made with caution. It has been suggested that the relationship between long sleep duration and adverse health could be the result of reversed causality, undiagnosed disease, residual confounding and the subjective reporting on sleep duration possibly representing time in bed $^{157}$. On the other hand, investigators are in general agreement that poor sleep quality increases the risk of obesity and T2DM. A meta-analysis showed that people with reduced subjective sleep quality are at increased risk of developing $\mathrm{T}_{2} \mathrm{DM}^{158}$. In line with this finding, patients with obstructive sleep apnoea are at increased risk of developing T2DM, which could be

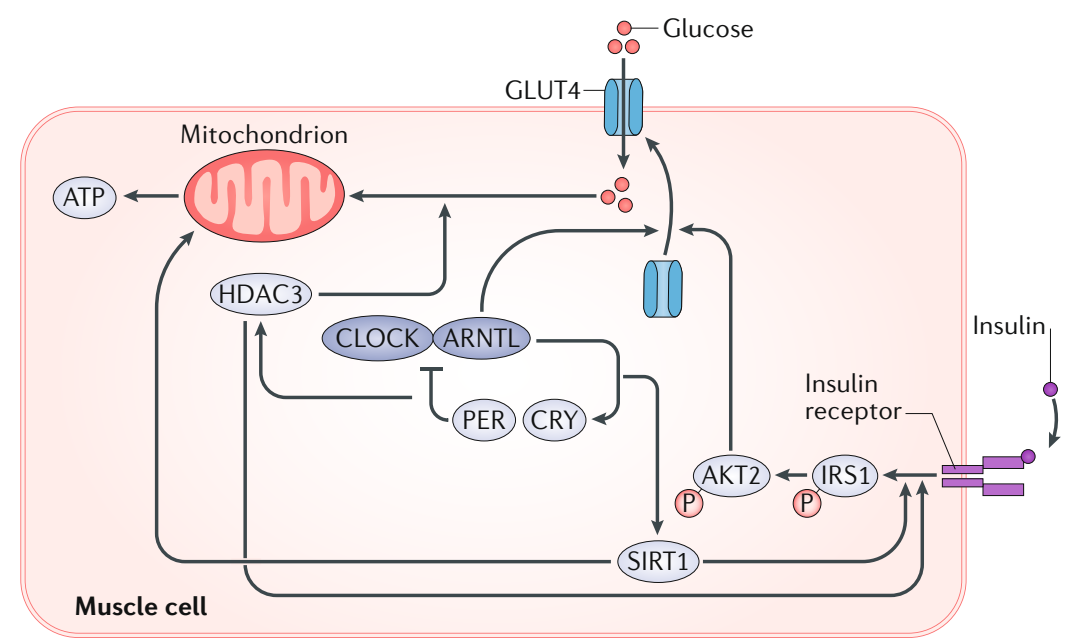

Fig. 5 | The muscle clock. In muscle, the muscle clock regulates muscle insulin sensitivity via protein levels and membrane translocation of the insulin-sensitive glucose transporter 4 (GLUT4) and through modulation of the insulin signalling pathway via expression of the deacetylase sirtuin 1 (SIRT1). In addition, the muscle clock regulates muscle insulin sensitivity via histone deacetylation of metabolic genes by histone deacetylase 3 (HDAC3). IRS1, insulin receptor substrate; P, phosphate. mediated by increased food intake and/or decreased physical activity ${ }^{159,160}$, among other mechanisms, owing to disturbed sleep ${ }^{161}$.

Several well-controlled human experimental studies shed further light on the relationship between sleep deprivation and insulin sensitivity. The seminal experimental study showed reduced glucose tolerance after five nights of chronic partial sleep loss ( $4 \mathrm{~h}$ per night) compared with five well-rested nights ( $12 \mathrm{~h}$ per night) in healthy human participants, under conditions of controlled food intake and physical activity ${ }^{162}$. Subsequent experimental studies under controlled conditions confirmed reduced liver ${ }^{163}$, adipose ${ }^{164}$ and whole-body ${ }^{163-168}$ insulin sensitivity as a result of sleep restriction to $4-6 \mathrm{~h}$ per night for 1-14 nights in healthy individuals. By contrast, other studies under controlled conditions found only short-term effects ${ }^{169}$ or no effect ${ }^{170}$ of sleep restriction on insulin sensitivity, which could be the result of milder sleep restriction ${ }^{169}$ or a mitigating effect of the negative energy balance owing to the experimental design ${ }^{170}$. Further to these observations, studies have shown that experimental slow-wave sleep suppression resulted in reduced whole-body insulin sensitivity in healthy individuals $\mathrm{s}^{171-173}$.

The proposed mechanisms for the effects of sleep restriction and sleep disturbance on insulin sensitivity include an altered sympatho-vagal balance ${ }^{162,171,172}$ and increased circulating levels of catecholamines ${ }^{167}$ or cortisol $^{167,172}$. In conditions of ad libitum food intake, increased food intake as a result of sleep restriction or disturbance probably contributes to decreased insulin sensitivity ${ }^{159,160}$.

A systematic review and meta-analysis showed that in patients with established T2DM, individuals who sleep for a short duration or a long duration and individuals with lower sleep quality have reduced glycaemic control compared with individuals who get adequate sleep ${ }^{174}$. Although several of the studies included in the systematic review and meta-analysis corrected for physical activity, the meta-analysis did not correct for food intake or physical activity, so it is possible that these correlations are partly confounded by increased food intake or decreased physical activity ${ }^{174}$.

The incidence of obstructive sleep apnoea is high in patients with T2DM. Furthermore, in patients with comorbid obstructive sleep apnoea and T2DM, poor glycaemic control correlates with the severity of obstructive sleep apnoea, a finding that could again be partly confounded by increased food intake and/or decreased physical activity ${ }^{161}$.

Chronotype and social jet lag. An individual's chronotype could also be a risk factor for insulin resistance. Observational studies show that evening chronotypes are at increased risk of developing T2DM compared with morning chronotypes ${ }^{175}$, even when results are corrected for sleep duration and physical activity (food intake was not corrected for in this study $)^{176}$. Some evidence suggests that this increased risk could be the result of increased social jet lag - the discrepancy between the social (behavioural) and endogenous (circadian) time. Individuals with an evening chronotype who are 


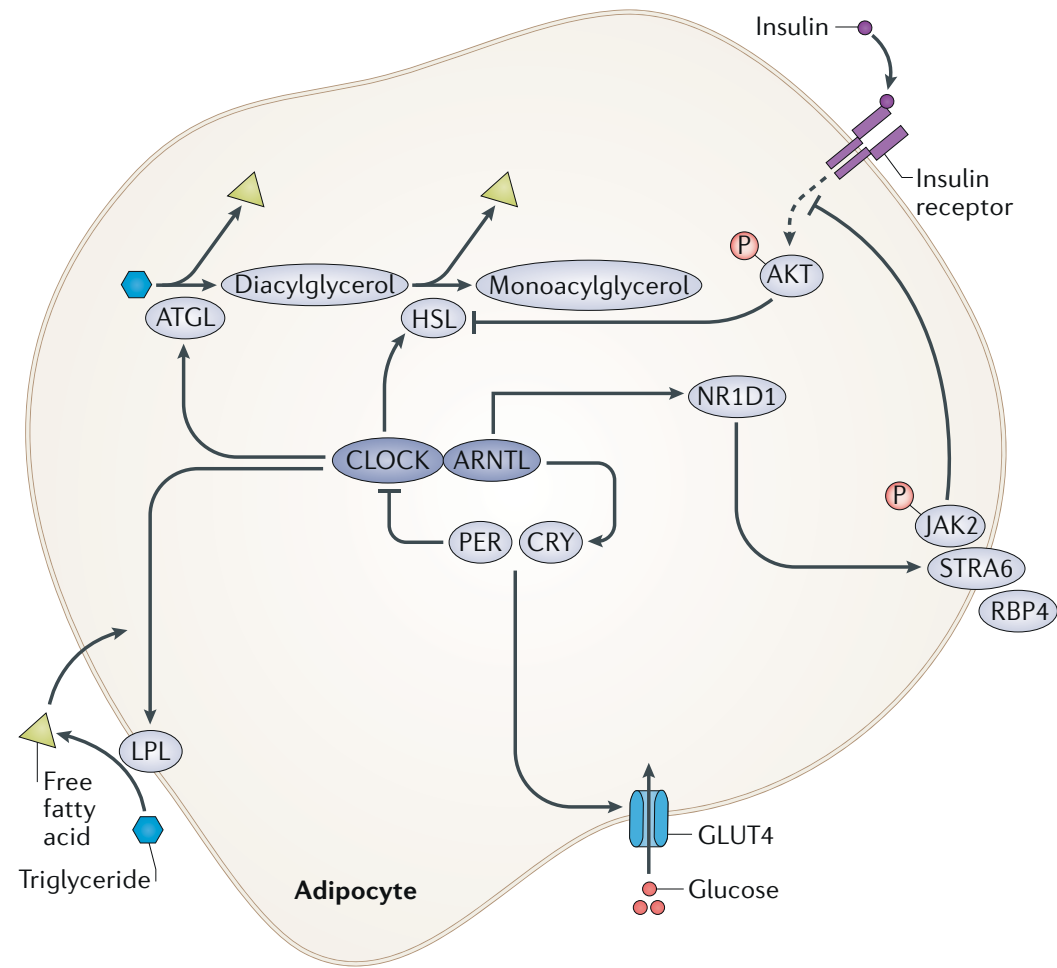

Fig. 6 | The white adipose tissue clock. In white adipose tissue, the circadian clock probably regulates the diurnal rhythm in insulin sensitivity via the circadian regulation of the retinol-binding protein receptor stimulated by retinoic acid 6 (STRA6). CLOCK and ARNTL regulate the expression of key enzymes in the regulation of lipolysis. ATGL, adipose triglyceride lipase; GLUT, glucose transporter; HSL, hormone-sensitive lipase; JAK2, Janus kinase 2; LPL, lipoprotein lipase; P, phosphate; RBP4, retinol-binding protein 4. cause increased food intake, increased body weight and disturbed glucose metabolism ${ }^{187}$. A 2014 translational study showed that repeated jet lag in mice causes reduced glucose tolerance via disturbance of the intestinal microbiome. Fascinatingly, faecal transfer from jet-lagged humans into germ-free mice also reduced glucose tolerance in mice, suggesting that the microbiome clock might have an important role in the development of insulin resistance owing to repeated phase shifts ${ }^{188}$.

Does circadian disruption contribute to insulin resistance? Taken together, the hypothesis that circadian disruption contributes to the development of insulin resistance in humans is supported by the following findings: decreased glucose tolerance caused by experimental circadian misalignment in humans; the association between human clock gene polymorphisms and insulin resistance; the experimentally observed effects of night-time light exposure and sleep disturbance on glucose metabolism; and the association of short sleep duration, long sleep duration, low sleep quality, late chronotype, social jet lag and shift work with insulin resistance. Therefore, it seems probable that disturbance of the central and/or tissue clock rhythms (FIG. 9) contributes to the pathophysiology of insulin resistance at the tissue level. Furthermore, circadian disruption might cause misalignment of nutrient fluxes. For instance, a mismatch between hepatic glucose production, muscle glucose uptake and carbohydrate intake could contribute to elevated levels of glucose and an imbalance between lipid storage in WAT, lipid oxidation in BAT and hepatic lipid production might contribute to ectopic lipid accumulation.

working regular daytime hours are at increased risk of social jet lag.

Social jet lag is associated with the development of T2DM, independently of sleep duration ${ }^{177-179}$, even when results are corrected for food intake and physical activity ${ }^{177}$. Patients with T2DM who are evening chronotypes show worse glycaemic control compared with patients who are morning chronotypes, a finding that might, in part, be mediated by an increase in evening food intake ${ }^{180}$; however, an association between poor glycaemic control and chronotype, independent of sleep duration, total food intake and physical activity, does also exist ${ }^{180,181}$.

Shift work and jet lag. Shift workers are at increased risk of developing T2DM, as shown by a 2015 meta-analysis of observational studies ${ }^{182}$; the degree of increased risk relates to the number of night shifts per month ${ }^{183}$. This increased risk of T2DM might be mediated by a combination of acute and chronic effects.

Experimental circadian misalignment under strictly controlled conditions acutely decreases glucose tolerance and insulin sensitivity both in non-shift workers and in chronic shift workers ${ }^{14,32,112,184-186}$. To our knowledge, the chronic effects of repeated phase shifts on food intake, physical activity and insulin sensitivity have not been studied experimentally in humans, but several animal studies show that repeated phase shifts

\section{Circadian synchrony and metabolic health Modulating light exposure}

Light provides the main input for the $\mathrm{SCN}$, and optimization of daily light exposure can therefore increase circadian synchrony ${ }^{140}$. To our knowledge, however, no published randomized controlled trials (RCTs) have investigated the effects of longterm natural light exposure on insulin sensitivity or glycaemia. ture and/or indoor lighting conditions. For example, one RCT showed that supplementing daytime indoor light conditions with bright artificial light in homes for the elderly improves cognitive functioning, sleep quality and the diurnal rhythm of locomotor activity ${ }^{189,190}$. Another study found that increasing blue light intensity in the morning with a system of wavelength-controlled light bulbs and LEDs at home improved subjective sleep quality in elderly women compared with low morning blue light intensity ${ }^{191}$.

A second potential strategy is to limit the use of screens from computers, tablets and smartphones in the evening, or to use blue light filters with these devices. An experimental study showed that reading a paper book in the evening reduced sleep-onset latency and improved daytime alertness the next day compared with reading a book on a light-emitting tablet ${ }^{192}$.
One potential strategy is the adaptation of architec- 


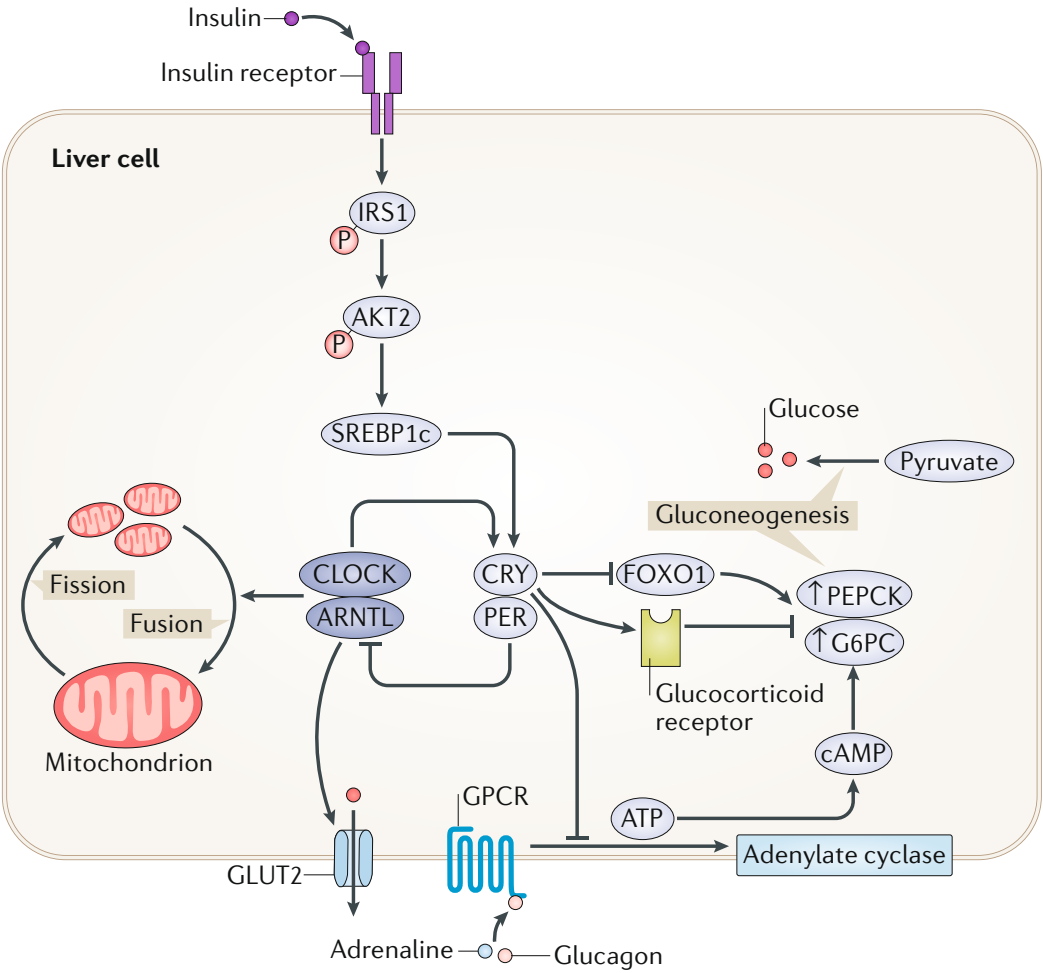

Fig. 7 | The liver clock. In the liver, the circadian repression of gluconeogenesis during the habitual feeding period is mediated by the interaction of $C R Y$ with the glucocorticoid receptor, G protein-coupled receptor (GPCR) signalling and FOXO1 degradation. The liver clock also regulates the diurnal rhythm in mitochondrial dynamics. FOXO1, forkhead box protein O1; G6PC, glucose 6 phosphatase; GLUT, glucose transporter; IRS1, insulin receptor substrate 1; P, phosphate; SREBP1c, sterol regulatory element-binding protein $1 \mathrm{c}$. sleep apnoea who had either normal glucose values or prediabetes. The authors found no effect on HOMAIR, but reported a small reduction of fasting insu$\operatorname{lin}^{198}$. A 2017 meta-analysis showed that treatment of obstructive sleep apnoea with CPAP does not improve levels of haemoglobin $\mathrm{A}_{1 \mathrm{c}}\left(\mathrm{HbA}_{1 \mathrm{c}}\right)$ or fasting levels of glucose in patients with obstructive sleep apnoea who have established T2DM, despite reduced daytime sleepiness ${ }^{199}$. The surprising lack of effect of CPAP treatment on glycaemia in patients with obstructive sleep apnoea could be related to treatment adherence ${ }^{199}$, as two studies with good adherence did show a decrease in $\mathrm{HbA}_{1 \mathrm{c}}\left(\mathrm{REF}^{200}\right)$ or mean $24 \mathrm{~h}$ glucose concentrations ${ }^{201}$.

Physical activity. Regular physical activity is one of the cornerstones of the lifestyle changes prescribed to patients with T2DM (FIG. 9). Regular physical exercise decreases insulin resistance and reduces $\mathrm{HbA}_{1 \mathrm{c}}\left(\mathrm{REF}^{202}\right)$. As physical activity also shifts the central circadian pacemaker in humans ${ }^{203}$, improves sleep duration and quality $^{204}$ and affects the muscle clock ${ }^{48,49}$, it is possible that some of the beneficial metabolic effects of (daytime) physical activity are mediated through the circadian timing system. To our knowledge, however, no studies have proved this idea. We are also not aware of any studies investigating the optimal timing of physical exercise for the reduction of body weight and insulin resistance.

Feeding behaviour. Individualized nutrition therapy is another core intervention in the prevention and treatment of insulin resistance and $\mathrm{T}_{2} \mathrm{DM}^{2}$. Classically, the main focus points for feeding behaviour are calorie reduction and healthy macronutrient distribution. An approach with a focus on the timing of food intake can also be of great value for people with insulin resistance $^{205}$. A 2017 systematic review on meal timing and frequency in the prevention of cardiovascular disease proposed an approach to eating that included the recommendations to eat a greater share of calories early in the day and to use consistent overnight fast periods $^{206}$ (FIG. 9).

The advice to consume a greater share of calories early in the day mainly results from RCTs showing that breakfast consumption (compared with breakfast skipping) improves insulin sensitivity ${ }^{207-210}$, although not all studies agree ${ }^{211,212}$. A hallmark study on the overnight fast in 156 North American individuals showed that most people do not consume the 'normal' three meals per day within $12 \mathrm{~h}$, but instead showed an irregular eating pattern spread over a $>15 \mathrm{hr}$ period. In that same study it was reported that a small group of eight people classed as obese who were treated with 'time-restricted feeding' (that is, they were asked to restrict eating to a $10 \mathrm{~h}$ period for 16 weeks) lost $3 \mathrm{~kg}$ in weight, which persisted over 1 year ${ }^{213}$. In line with this finding, a 2018 randomized crossover trial in eight individuals with prediabetes showed that isocaloric early time-restricted feeding (that is, a $6 \mathrm{~h}$ feeding period with dinner before $15: 00 \mathrm{~h}$ ) reduces insulin resistance compared with a $12 \mathrm{~h}$ feeding period ${ }^{214}$. 


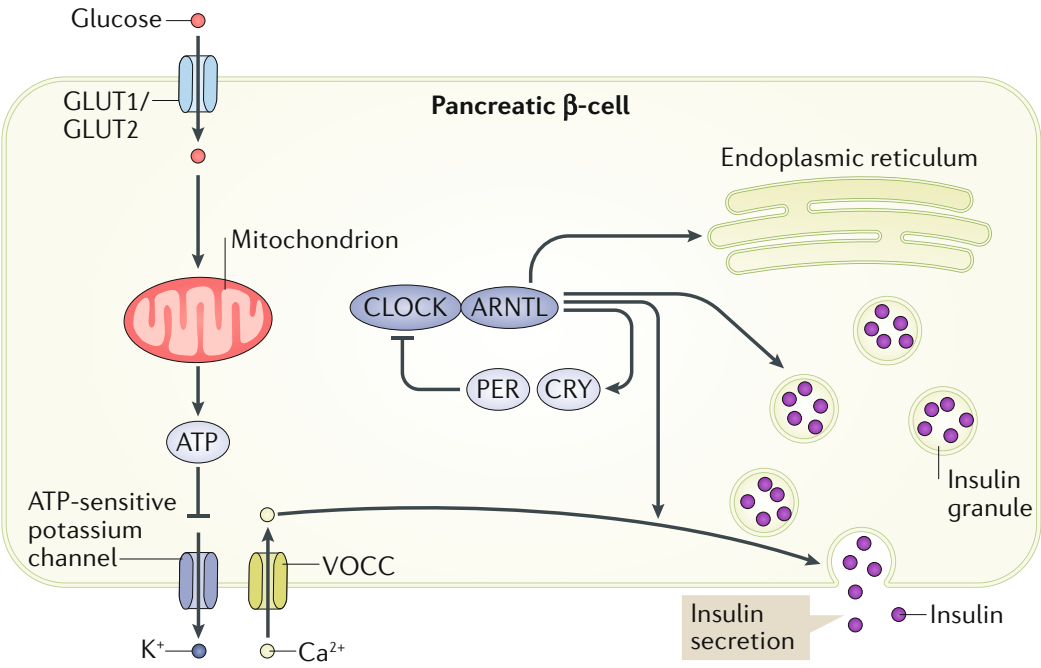

Fig. 8 | The pancreas clock. In the pancreas, CLOCK and BMAL1 activate the transcription of genes involved in insulin biosynthesis, insulin transport and glucose-stimulated insulin secretion. All depicted processes show circadian rhythmicity. GLUT, glucose transporter; VOCC, voltage-dependent calcium channel.
$\mathrm{HbA}_{1 \mathrm{c}}$ and fasting levels of glucose in patients with $\mathrm{T}_{2} \mathrm{DM}^{2,222}$. To our knowledge, however, no human trials have compared the effects of different administration times, which would be the ultimate proof that bromocriptine treatment is actually a chronotherapy.

The effects of timed melatonin administration in patients with T2DM have been investigated in one small RCT with 36 participants, which compared 3 weeks of melatonin administration with placebo ${ }^{223}$. The investigators reported no convincing evidence of beneficial metabolic effects of melatonin.

The insulin requirements of patients on insulin therapy vary over the diurnal cycle owing to the diurnal rhythms of sleep-wake behaviour, physical activity, food intake and insulin sensitivity. The research community has made tremendous efforts to improve insulin pharmacokinetics with the aim of matching them to the individual patient's diurnal pattern in insulin requirements $^{224,225}$. The question of whether the beneficial effects of insulin are (partly) mediated through central or peripheral clock modulation, however, remains to be resolved.

The artificial pancreas - which consists of an insulin pump controlled by a control algorithm coupled to a continuous glucose sensor ${ }^{226}$ - was in 2016 shown to increase the length of time spent in target glucose ranges in patients with T2DM who had been admitted to hospital ${ }^{227}$. One possible approach to further improve the algorithm controlling the artificial pancreas for patients with T2DM would be to incorporate information on the diurnal rhythm of insulin sensitivity.

The administration of exogenous glucocorticoids causes insulin resistance ${ }^{23}$. Data from a subgroup analysis of a small open-label randomized trial ${ }^{228}$ and two prospective cohort studies ${ }^{229,230}$ suggest once-daily modified-release hydrocortisone formulations might be beneficial for metabolic health compared with thricedaily immediate-release hydrocortisone. Analysis of the small subgroup of patients with comorbid adrenal insufficiency and diabetes mellitus showed that replacement therapy with once-daily modified-release hydrocortisone formulations (which mimic the physiological diurnal rhythm of cortisol levels) might lead to improvements in body weight and $\mathrm{HbA}_{1 \mathrm{c}}$ compared with thrice-daily immediate-release hydrocortisone.

\section{Circadian molecules}

New circadian therapies might arise from large-scale chemical screens looking for clock-improving molecules $^{231-233}$ (FIG. 9). Promising candidates include the REV-ERB $\alpha$ agonist SR9011 and the REV-ERB $\beta$ agonist SR9009, both of which directly target the molecular clock and were shown to decrease obesity and hyperglycaemia in diet-induced obese mice. Timed twicedaily administration of these REV-ERB agonists alters metabolic gene expression patterns in muscle and WAT, leading to increased muscle glucose and fatty acid oxidation (increased energy expenditure), in combination with decreased WAT triglyceride synthesis ${ }^{234}$.

Another promising candidate is the natural citrus compound nobiletin, which has been shown to reduce body weight and improve insulin sensitivity 

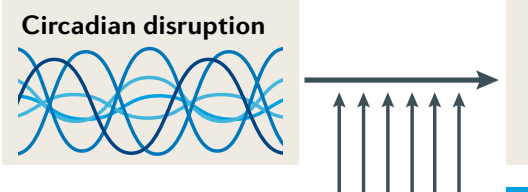

Circadian synchrony

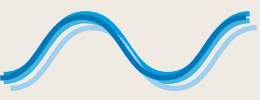

Light-dark exposure

- Increase daytime light

- Decrease light at night

and screen use

\section{Circadian molecules}

- REV-ERB agonists

- CRY stabilizers

- ROR agonists
Daytime physical activity
Sleep-wake behaviour

- Regular sleep-wake cycle

- Refrain from shift work

- Improve sleep quality

- Identify and treat obstructive sleep apnoea

Chronotherapy for type 2 diabetes mellitus

- Bromocriptine quick release

- Modified-release hydrocortisone in patients with adrenal insufficiency
Fig. 9 | Potential interventions promoting metabolic health through circadian synchrony. Improving the synchrony between behavioural fasting-feeding and sleepwake rhythms, hormonal and autonomic nervous system rhythms, and central and peripheral clock rhythms, might prove a valuable approach to prevent and/or treat insulin resistance and type 2 diabetes mellitus. Therapeutic interventions to improve circadian synchrony are possible at several levels: the light input to the circadian timing system; the behavioural level (sleep-wake behaviour, physical activity and food intake), directly targeting the molecular clock and the timing of medication (chronotherapy). Dark blue boxes show information that has some clinical human evidence supporting an effect on insulin sensitivity. Light blue boxes show information that has no clinical evidence supporting an effect on insulin sensitivity. in two different mouse models of the metabolic syndrome (diet-induced obese mice and $d b / d b$ mice). Nobiletin directly targets the molecular clock by activating ROR $\alpha$ and ROR $\gamma$, thus increasing the amplitude of circadian locomotor behaviour, the rhythm of tissue clock gene expression and the rhythm of hepatic metabolic gene expression. As a result, energy expenditure increases, adiposity decreases and hepatic steatosis decreases ${ }^{235}$. Finally, in preliminary reports, two different CRY stabilizers were shown to improve glucose tolerance in diet-induced obese mice ${ }^{236}$ and $d b / d b$ mice $^{237}$. The exact mechanism responsible for these metabolic benefits, however, remains to be elucidated.

In conclusion, REV-ERB agonists, ROR agonists and CRY stabilizers are promising circadian molecules for the treatment of T2DM, and human phase I studies of these compounds are to be expected.

\section{Conclusions}

Despite the large body of evidence from animal studies, the exact mechanisms mediating the metabolic derangements resulting from circadian disruption remain to be resolved. For example, does circadian misalignment cause a mismatch of glucose and lipid fluxes between the various organs or do disrupted tissue clocks cause insulin resistance at the tissue level, or are both mechanisms involved?

Currently, the clinical utility of the knowledge on circadian clock regulation of insulin sensitivity is only beginning to be explored. A clear need exists for RCTs that investigate the metabolic effects of natural light-dark exposure, sleep improvement, time-restricted feeding and the daily timing of exercise. Clinical trials are needed that investigate methods to prevent metabolic complications in shift workers. With regard to biomarkers, evidence suggests that circadian phase biomarkers can help to optimally synchronize the circadian timing of behavioural or pharmacological interventions ${ }^{238}$. We are in no doubt that new circadian molecules targeting the molecular clock will be identified within the next 10 years. Furthermore, mathematical models could be an important aid to predict the effects of timed administration of clock agonists ${ }^{239}$. We expect the further development of promising candidate circadian molecules, including nobiletin, in phase I human trials in the coming years.

Published online 7 December 2018
1. World Health Organization. Global Report on Diabetes (WHO, 2016).

2. American Diabetes Association. Standards of medical care in diabetes-2018. Diabetes Care 41, S1-S159 (2018).

2018 Current guideline of the American Diabetes Association for the diagnosis and treatment of diabetes mellitus.

3. Ouyang, Y., Andersson, C. R., Kondo, T., Golden, S. S. \& Johnson, C. H. Resonating circadian clocks enhance fitness in cyanobacteria. Proc. Natl Acad. Sci. USA 95, 8660-8664 (1998).

4. Woelfle, M. A., Ouyang, Y., Phanvijhitsiri, K. \& Johnson, C. H. The adaptive value of circadian clocks: an experimental assessment in cyanobacteria. Curr. Biol. 14, 1481-1486 (2004).

5. Dibner, C., Schibler, U. \& Albrecht, U. The mammalian circadian timing system: organization and coordination of central and peripheral clocks. Annu. Rev. Physiol. 72, 517-549 (2010).

6. Stenvers, D. J., Jonkers, C. F., Fliers, E., Bisschop, P. H. $\&$ Kalsbeek, A. Nutrition and the circadian timing system. Progress Brain Res. 199, 359-376 (2012).

7. Lowrey, P. L. \& Takahashi, J. S. Mammalian circadian biology: elucidating genome-wide levels of temporal organization. Annu. Rev. Genom. Hum. Genet. 5, 407-441 (2004)

8. Reppert, S. M. $\&$ Weaver, D. R. Coordination of circadian timing in mammals. Nature 418, 935-941 (2002).

9. Roberts, H. J. Afternoon glucose tolerance testing: a key to the pathogenesis, early diagnosis and prognosis of diabetogenic hyperinsulinism. J. Am. Geriatr. Soc. 12, 423-472 (1964).

10. Van Cauter, E., Polonsky, K. S. \& Scheen, A. J. Roles of circadian rhythmicity and sleep in human glucose regulation. Endocr. Rev. 18, 716-738 (1997).

Seminal review on the diurnal rhythms of human glucose metabolism.

11. Gibson, T. \& Jarrett, R. J. Diurnal variation in insulin sensitivity. Lancet 2, 947-948 (1972).

12. Boden, G., Ruiz, J., Urbain, J. L. \& Chen, X. Evidence for a circadian rhythm of insulin secretion. Am. J. Physiol. 271, E246-E252 (1996).

13. Saad, A. et al. Diurnal pattern to insulin secretion and insulin action in healthy individuals. Diabetes 61 , 2691-2700 (2012).

14. Morris, C. J. et al. Endogenous circadian system and circadian misalignment impact glucose tolerance via separate mechanisms in humans. Proc. Natl Acad. Sci. USA 112, E2225-E2234 (2015).

15. Stephan, F. K. \& Zucker, I. Circadian rhythms in drinking behavior and locomotor activity of rats are eliminated by hypothalamic lesions. Proc. Natl Acad Sci. USA 69, 1583-1586 (1972).

16. Czeisler, C. A., Weitzman, E., Moore-Ede, M. C. Zimmerman, J. C. \& Knauer, R. S. Human sleep: its duration and organization depend on its circadian phase. Science 210, 1264-1267 (1980).

17. Saper, C. B., Scammell, T. E. \& Lu, J. Hypothalamic regulation of sleep and circadian rhythms. Nature 437, 1257-1263 (2005)
18. Strubbe, J. H. \& van Dijk, G. The temporal organization of ingestive behaviour and its interaction with regulation of energy balance. Neurosci. Biobehav. Rev. 26, 485-498 (2002).

19. Scheer, F. A., Morris, C. J. \& Shea, S. A. The internal circadian clock increases hunger and appetite in the evening independent of food intake and other behaviors. Obesity 21, 421-423 (2013). First study showing the control of human appetite by the endogenous circadian timing system.

20. Herrera-Moro Chao, D. et al. The suprachiasmatic nucleus modulates the sensitivity of arcuate nucleus to hypoglycemia in the male rat. Endocrinology 157 , 3439-3451 (2016).

21. Blancas-Velazquez, A., Mendoza, J., Garcia, A. N. \& la Fleur, S. E. Diet-induced obesity and circadian disruption of feeding behavior. Front. Neurosci. 11, 23 (2017)

22. Buckley, T. M. \& Schatzberg, A. F. On the interactions of the hypothalamic-pituitary-adrenal (HPA) axis and sleep: normal HPA axis activity and circadian rhythm, exemplary sleep disorders. J. Clin. Endocrinol. Metab. 90, 3106-3114 (2005)

23. van Raalte, D. H. $\&$ Diamant, M. Steroid diabetes: from mechanism to treatment? Neth. J. Med. 72, 62-72 (2014)

24. Ramracheya, R. D. et al. Function and expression of melatonin receptors on human pancreatic islets. J. Pineal Res. 44, 273-279 (2008).

25. Tuomi, T. et al. Increased melatonin signaling is a risk factor for type 2 diabetes. Cell Metab. 23, 1067-1077 (2016). 
26. Claustrat, B., Brun, J. \& Chazot G. The basic physiology and pathophysiology of melatonin. Sleep Med. Rev. 9, 11-24 (2005).

27. Moller, N. \& Jorgensen, J. O. Effects of growth hormone on glucose, lipid, and protein metabolism in human subjects. Endocr. Rev. 30, 152-177 (2009).

28. Morris, C. J., Aeschbach, D. \& Scheer, F. A. Circadian system, sleep and endocrinology. Mol. Cell. Endocrinol. 349, 91-104 (2012).

29. Willoughby, J. O. \& Martin, J. B. The suprachiasmatic nucleus synchronizes growth hormone secretory rhythms with the light-dark cycle. Brain Res. 151 413-417 (1978)

30. La Fleur, S. E., Kalsbeek, A., Wortel, J., Fekkes, M. L. $\S$ Buijs, R. M. A daily rhythm in glucose tolerance: a role for the suprachiasmatic nucleus. Diabetes 50, 1237-1243 (2001)

31. Coomans, C. P. et al. The suprachiasmatic nucleus controls circadian energy metabolism and hepatic insulin sensitivity. Diabetes 62, 1102-1108 (2013).

32. Morris, C. J., Purvis, T. E., Mistretta, J. \& Scheer, F. A. Effects of the internal circadian system and circadian misalignment on glucose tolerance in chronic shift workers. J. Clin. Endocrinol. Metab. 101, 1066-1074 (2016).

33. Morris, C. J. et al. The human circadian system has a dominating role in causing the morning/evening difference in diet-induced thermogenesis. Obesity 23, 2053-2058 (2015)

34. Krauchi, K. \& Wirz-Justice, A. Circadian rhythm of heat production, heart rate, and skin and core temperature under unmasking conditions in men. Am. J. Physiol. 267, R819-R829 (1994)

35. Moran-Ramos, S. et al. The suprachiasmatic nucleus drives day-night variations in postprandial triglyceride uptake into skeletal muscle and brown adipose tissue. Exp. Physiol. 102, 1584-1595 (2017).

36. Amir, S., Shizgal, P. \& Rompre, P. P. Glutamate injection into the suprachiasmatic nucleus stimulates brown fat thermogenesis in the rat. Brain Res. $\mathbf{4 9 8}$, 140-144 (1989)

37. Bamshad, M., Song, C. K. \& Bartness, T. J. CNS origins of the sympathetic nervous system outflow to brown adipose tissue. Am. J. Physiol. 276 R1569-R1578 (1999).

38. Hussain, M. M. \& Pan, X. Circadian regulation of macronutrient absorption. J. Biol. Rhythms 30, 459-469 (2015)

39. Scheving, L. A. Biological clocks and the digestive system. Gastroenterology 119, 536-549 (2000).

40. Hoogerwerf, W. A. Role of clock genes in gastrointestinal motility. Am. J. Physiol. Gastrointest. Liver Physiol. 299, G549-G555 (2010).

41. Iwashina, I., Mochizuki, K., Inamochi, Y. \& Goda, T Clock genes regulate the feeding schedule-dependent diurnal rhythm changes in hexose transporter gene expressions through the binding of BMAL1 to the promoter/enhancer and transcribed regions. J. Nutr. Biochem. 22, 334-343 (2011).

42. Nishida, T., Saito, M. \& Suda, M. Parallel between circadian rhythms of intestinal disaccharidases and food intake of rats under constant lighting conditions. Gastroenterology 74, 224-227 (1978).

43. Saito, M., Kato, H. \& Suda, M. Circadian rhythm of intestinal disaccharidases of rats fed with adiurnal periodicity. Am. J. Physiol. 238, G97-G101 (1980).

44. Hansen, J et al Synchronized human skeleta myotubes of lean, obese and type 2 diabetic patients maintain circadian oscillation of clock genes. Sci. Rep. 6, 35047 (2016)

45. Perrin, L. et al. Human skeletal myotubes display a cell-autonomous circadian clock implicated in basal myokine secretion. Mol. Metab. 4, 834-845 (2015).

46. Guo, H., Brewer, J. M., Lehman, M. N. \& Bittman, E. L. Suprachiasmatic regulation of circadian rhythms of gene expression in hamster peripheral organs: effects of transplanting the pacemaker. J. Neurosci. 26, 6406-6412 (2006)

47. Guo, H., Brewer, J. M., Champhekar, A., Harris, R. B. \& Bittman, E. L. Differential control of peripheral circadian rhythms by suprachiasmatic-dependent neural signals. Proc. Natl Acad. Sci. USA 102. 3111-3116 (2005)

48. Yamanaka, Y., Honma, S. \& Honma, K. Scheduled exposures to a novel environment with a runningwheel differentially accelerate re-entrainment of mice peripheral clocks to new light-dark cycles. Genes Cells 13, 497-507 (2008)

49. Wolff, G. \& Esser, K. A. Scheduled exercise phase shifts the circadian clock in skeletal muscle. Med. Sci. Sports Exercise 44, 1663-1670 (2012).
50. Reznick, J. et al. Altered feeding differentially regulates circadian rhythms and energy metabolism in liver and muscle of rats. Biochim. Biophys. Acta 1832 228-238 (2013)

51. Opperhuizen, A. L. et al. Feeding during the resting phase causes profound changes in physiology and desynchronization between liver and muscle rhythms of rats. Eur. J. Neurosci. 44, 2795-2806 (2016).

52. Feneberg, R. \& Lemmer, B. Circadian rhythm of glucose uptake in cultures of skeletal muscle cells and adipocytes in Wistar-Kyoto, Wistar, Goto-Kakizaki, and spontaneously hypertensive rats. Chronobiol. Int. 21 , 521-538 (2004)

53. Dyar, K. A. et al. Muscle insulin sensitivity and glucose metabolism are controlled by the intrinsic muscle clock. Mol. Metab. 3, 29-41 (2014).

54. Liu, J. et al. CLOCK and BMAL1 regulate muscle insulin sensitivity via SIRT 1 in male mice. Endocrinology 157, 2259-2269 (2016).

55. Hong, S. et al. Dissociation of muscle insulin sensitivity from exercise endurance in mice by HDAC3 depletion. Nat. Med. 23, 223-234 (2017).

56. Verrillo, A. et al. Differential roles of splanchnic and peripheral tissues in determining diurnal fluctuation of glucose tolerance. Am. J. Physiol. 257, E459-E465 (1989).

57. van Moorsel, D. et al. Demonstration of a day-night rhythm in human skeletal muscle oxidative capacity. Mol. Metab. 5, 635-645 (2016)

58. Otway, D. T., Frost, G. \& Johnston, J. D. Circadian rhythmicity in murine pre-adipocyte and adipocyte cells. Chronobiol. Int. 26, 1340-1354 (2009).

59. Ramanathan, C. et al. Cell type-specific functions of period genes revealed by novel adipocyte and hepatocyte circadian clock models. PLOS Genet. 10 e1004244 (2014).

60. Huang, T. S. et al. Induction of circadian rhythm in cultured human mesenchymal stem cells by serum shock and cAMP analogs in vitro. Chronobiol. Int. 26, 242-257 (2009)

61. Gomez-Santos, C. et al. Circadian rhythm of clock genes in human adipose explants. Obesity 17 1481-1485 (2009).

62. Kolbe, I. et al. The SCN clock governs circadian transcription rhythms in murine epididymal white adipose tissue. J. Biol. Rhythms 31, 577-587 (2016)

63. Wehrens, S. M. T. et al. Meal timing regulates the human circadian system. Curr. Biol. 27, 1768-1775 (2017).

Study demonstrating the effect of meal timing on adipose tissue clock gene expression in humans.

64. Su, Y., Foppen, E., Zhang, Z., Fliers, E. \& Kalsbeek, A Effects of 6-meals-a-day feeding and 6-meals-a-day feeding combined with adrenalectomy on daily gene expression rhythms in rat epididymal white adipose tissue. Genes Cells 21, 6-24 (2016).

65. Loboda, A et al. Diurnal variation of the human adipose transcriptome and the link to metabolic disease. BMC. Med. Genom. 2, 7 (2009).

66. Carrasco-Benso, M. P. et al. Human adipose tissue expresses intrinsic circadian rhythm in insulin sensitivity. FASEB J. 30, 3117-3123 (2016). First study showing a circadian rhythm in insulin signalling in cultured white adipose tissue explants from humans.

67. Gliniak, C. M., Brown, J. M. \& Noy, N. The retinobinding protein receptor STRA6 regulates diurnal insulin responses. J. Biol. Chem. 292, 15080-15093 (2017).

68. Delezie, J. et al. The nuclear receptor REV-ERBalpha is required for the daily balance of carbohydrate and lipid metabolism. FASEB J. 26, 3321-3335 (2012).

69. Shostak, A., Meyer-Kovac, J. \& Oster, H. Circadian regulation of lipid mobilization in white adipose tissues. Diabetes 62, 2195-2203 (2013)

70. van der Veen, D. R., Shao, J., Chapman, S., Leevy, W. M. $\&$ Duffield, G. E. A diurnal rhythm in glucose uptake in brown adipose tissue revealed by in vivo PET-FDG imaging. Obesity 20, 1527-1529 (2012).

71. Lee, P. et al. Brown adipose tissue exhibits a glucose-responsive thermogenic biorhythm in humans Cell Metab. 23, 602-609 (2016)

72. Sakamoto, K. et al. Multitissue circadian expression of rat period homolog (rPer2) mRNA is governed by the mammalian circadian clock, the suprachiasmatic nucleus in the brain. J. Biol. Chem. 273 27039-27042 (1998)

73. Akhtar, R. A. et al. Circadian cycling of the mouse liver transcriptome, as revealed by CDNA microarray, is driven by the suprachiasmatic nucleus. Curr. Biol. 12, 540-550 (2002).
74. Stokkan, K. A., Yamazaki, S., Tei, H., Sakaki, Y. \& Menaker, M. Entrainment of the circadian clock in the liver by feeding. Science 291, 490-493 (2001).

75. Panda, S. et al. Coordinated transcription of key pathways in the mouse by the circadian clock. Cell 109, 307-320 (2002)

76. Kornmann, B., Schaad, O., Bujard, H Takahashi, J. S. \& Schibler, U. System-driven and oscillator-dependent circadian transcription in mice with a conditionally active liver clock. PLOS Biol. 5, e34 (2007).

77. Robles, M. S., Cox, J. \& Mann, M. In-vivo quantitative proteomics reveals a key contribution of posttranscriptional mechanisms to the circadian regulation of liver metabolism. PLOS Genet. 10, e1004047 (2014).

78. Mauvoisin, D. et al. Circadian clock-dependent and -independent rhythmic proteomes implement distinct diurnal functions in mouse liver. Proc. Natl Acad. Sci. USA 111, 167-172 (2014).

79. Gooley, J. J. \& Chua, E. C. Diurnal regulation of lipid metabolism and applications of circadian lipidomics. J. Genet. Genomics 41, 231-250 (2014).

80. Abbondante, S., Eckel-Mahan, K. L., Ceglia, N. J. Baldi, P. \& Sassone-Corsi, P. Comparative circadian metabolomics reveal differential effects of nutritional challenge in the serum and liver. J. Biol. Chem. 291, 2812-2828 (2016).

81. Krishnaiah, S. Y et al. Clock regulation of metabolites reveals coupling between transcription and metabolism. Cell Metab. 25, 1206 (2017).

82. Lamia, K. A., Storch, K. F. \& Weitz, C. J. Physiological significance of a peripheral tissue circadian clock. Proc. Natl Acad. Sci. USA 105, 15172-15177 (2008). Key study showing that the hepatic clock is essential to maintain euglycemia during the fasting period in mice.

83. Rudic, R. D. et al. BMAL1 and CLOCK, two essential components of the circadian clock, are involved in glucose homeostasis. PLOS Biol. 2, e377 (2004).

84. Lamia, K. A. et al. Cryptochromes mediate rhythmic repression of the glucocorticoid receptor. Nature $\mathbf{4 8 0}$ 552-556 (2011).

85. Zhang, E. E. et al. Cryptochrome mediates circadian regulation of CAMP signaling and hepatic gluconeogenesis. Nat. Med. 16, 1152-1156 (2010).

86. Jang, H. et al. SREBP $1 \mathrm{c}-\mathrm{CRY} 1$ signalling represses hepatic glucose production by promoting FOXO1 degradation during refeeding. Nat. Commun. $\mathbf{7}$, 12180 (2016)

87. Tong, $X$. et al. DDB1-mediated $C R Y 1$ degradation promotes FOXO1-driven gluconeogenesis in liver Diabetes 66, 2571-2582 (2017).

88. Macauley, M., Smith, F. E., Thelwall, P. E. Hollingsworth, K. G. \& Taylor, R. Diurnal variation in skeletal muscle and liver glycogen in humans with normal health and Type 2 diabetes. Clin. Sci. 128, 707-713 (2015)

89. Peek, C. B et al. Circadian clock interaction with HIF 1 a mediates oxygenic metabolism and anaerobic glycolysis in skeletal muscle. Cell Metab. 25, 86-92 (2017)

90. Neufeld-Cohen, A. et al. Circadian control of oscillations in mitochondrial rate-limiting enzymes and nutrient utilization by PERIOD proteins. Proc. Natl Acad. Sci. USA 113, E1673-E1682 (2016).

91. Jacobi, D. et al. Hepatic Bmal1 regulates rhythmic mitochondrial dynamics and promotes metabolic fitness. Cell Metab. 22, 709-720 (2015).

92. Vieira, E., Burris, T. P. \& Quesada, I. Clock genes, pancreatic function, and diabetes. Trends Mol. Med. 20, 685-693 (2014)

93. Peschke, E. \& Peschke, D. Evidence for a circadian rhythm of insulin release from perifused rat pancreatic slets. Diabetologia 41, 1085-1092 (1998).

94. Marcheva, B. et al. Disruption of the clock components CLOCK and BMAL1 leads to hypoinsulinaemia and diabetes. Nature 466, 627-631 (2010).

Pivotal study showing that specific ablation of the pancreatic clock disrupts insulin secretion in mice.

95. Qian, J., Block, G. D., Colwell, C. S. \& Matveyenko, A. V. Consequences of exposure to light at night on the pancreatic islet circadian clock and function in rats. Diabetes 62, 3469-3478 (2013).

96. Pulimeno, P. et al. Autonomous and self-sustained circadian oscillators displayed in human islet cells. Diabetologia 56, 497-507 (2013).

97. Saini, C. et al. A functional circadian clock is required for proper insulin secretion by human pancreatic slet cells. Diabetes Obes. Metab. 18, 355-365 (2016).

Study demonstrating that CLOCK inhibition with small interfering RNA disrupts insulin secretion in cultured human pancreatic islet cells. 
98. Buijs, R. M., Chun, S. J., Niijima, A., Romijn, H. J. \& Nagai, K. Parasympathetic and sympathetic control of the pancreas: a role for the suprachiasmatic nucleus and other hypothalamic centers that are involved in the regulation of food intake. J. Comp. Neurol. 431 405-423 (2001)

99. Perelis, M. et al. Pancreatic beta cell enhancers regulate rhythmic transcription of genes controlling insulin secretion. Science 350, aac4250 (2015).

100. Sadacca, L. A., Lamia, K. A., deLemos, A. S., Blum, B. $\&$ Weitz, C. J. An intrinsic circadian clock of the pancreas is required for normal insulin release and glucose homeostasis in mice. Diabetologia $\mathbf{5 4}$, 120-124 (2011).

101. Lee, J. et al. Loss of Bmal 1 leads to uncoupling and impaired glucose-stimulated insulin secretion in $\beta$ cells. Islets 3, 381-388 (2011)

102. Defronzo, R. A. Banting lecture. From the triumvirate to the ominous octet: a new paradigm for the treatment of type 2 diabetes mellitus. Diabetes $\mathbf{5 8}$, 773-795 (2009)

103. Shulman, G. I. Cellular mechanisms of insulin resistance. J. Clin. Invest. 106, 171-176 (2000).

104. Shulman, G. I. et al. Quantitation of muscle glycogen synthesis in normal subjects and subjects with noninsulin-dependent diabetes by $13 \mathrm{C}$ nuclear magnetic resonance spectroscopy. N. Engl. J. Med. 322, 223-228 (1990)

105. Reaven, G. M., Chen, Y. D., Donner, C. C., Fraze, E. \& Hollenbeck, C. B. How insulin resistant are patients with noninsulin-dependent diabetes mellitus? J. Clin. Endocrinol. Metab. 61, 32-36 (1985).

106. Winocour, P. H. et al. A randomized cross-over study of the effects of proinsulin on lipid metabolism in type 2 diabetes. Diabet. Med. 8, 22-27 (1991).

107. Meek, S. E., Nair, K. S. \& Jensen, M. D. Insulin regulation of regional free fatty acid metabolism. Diabetes 48, 10-14 (1999).

108. Unger, R. H. Minireview: weapons of lean body mass destruction: the role of ectopic lipids in the metabolic syndrome. Endocrinology 144, 5159-5165 (2003).

109. Jarrett, R. J. \& Keen, H. Diurnal variation of oral glucose tolerance: a possible pointer to the evolution of diabetes mellitus. Br. Med. J. 2, 341-344 (1969). First study showing an altered daily rhythm in glucose tolerance in patients with type 2 diabetes mellitus.

110. Turek, F. W. et al. Obesity and metabolic syndrome in circadian Clock mutant mice. Science $\mathbf{3 0 8}$, 1043-1045 (2005)

First study to show metabolic disease in a clock gene knockout mouse.

111. Arble, D. M., Bass, J., Laposky, A. D., Vitaterna, M. H. $\&$ Turek, F. W. Circadian timing of food intake contributes to weight gain. Obes.(Silver. Spring) 17, 2100-2102 (2009)

112. Scheer, F. A., Hilton, M. F., Mantzoros, C. S. \& Shea, S. A. Adverse metabolic and cardiovascular consequences of circadian misalignment. Proc. Natl Acad. Sci. USA 106, 4453-4458 (2009). First study demonstrating that humans develop reduced glucose tolerance when subjected to conditions of circadian misalignment.

113. Bass, J. \& Takahashi, J. S. Circadian integration of metabolism and energetics. Science 330 , 1349-1354 (2010).

114. Lee, J. et al. Bmal1 and $\beta$-cell clock are required for adaptation to circadian disruption, and their loss of function leads to oxidative stress-induced beta-cell failure in mice. Mol. Cell. Biol. 33, 2327-2338 (2013).

115. Harfmann, B. D. et al. Muscle-specific loss of Bmal 1 leads to disrupted tissue glucose metabolism and systemic glucose homeostasis. Skelet. Muscle 6, 12 (2016).

116. Paschos, G. K. et al. Obesity in mice with adipocytespecific deletion of clock component Arntl. Nat. Med. 18, 1768-1777 (2012)

117. Oishi, K. et al. Disrupted fat absorption attenuates obesity induced by a high-fat diet in Clock mutant mice. FEBS Lett. 580, 127-130 (2006).

118. Zani, F. et al. PER2 promotes glucose storage to liver glycogen during feeding and acute fasting by inducing Gys2 PTG and G L expression. Mol. Metab. 2 292-305 (2013).

119. Grimaldi, B. et al. PER2 controls lipid metabolism by direct regulation of PPARgamma. Cell Metab. 12, 509-520 (2010)

120. Stenvers, D. J. et al. Dim light at night disturbs the daily sleep-wake cycle in the rat. Sci. Rep. 6, 35662 (2016).

121. Shamsi, N. A. et al. Metabolic consequences of timed feeding in mice. Physiol. Behav. 128, 188-201 (2014).
122. Sherman, H. et al. Timed high-fat diet resets circadian metabolism and prevents obesity. FASEB J. 26 3493-3502 (2012).

123. Kalsbeek, A., la Fleur, S. \& Fliers, E. Circadian control of glucose metabolism. Mol. Metab. 3, 372-383 (2014).

124. Eckel-Mahan, K. \& Sassone-Corsi, P. Metabolism and the circadian clock converge. Physiol. Rev. 93, 107-135 (2013)

125. Fonken, L. K. \& Nelson, R. J. The effects of light at night on circadian clocks and metabolism. Endocr. Rev. 35, 648-670 (2014).

126. Woon, P. Y. et al. Aryl hydrocarbon receptor nuclear translocator-like (BMAL1) is associated with susceptibility to hypertension and type 2 diabetes. Proc. Natl Acad. Sci. USA 104, 14412-14417 (2007). First study showing an association between a clock gene single nucleotide polymorphism and type 2 diabetes mellitus.

127. Scott, E. M., Carter, A. M. \& Grant, P. J. Association between polymorphisms in the Clock gene, obesity and the metabolic syndrome in man. Int. J. Obes. 32 , 658-662 (2008)

128. Sookoian, S. et al. Genetic variants of Clock transcription factor are associated with individual susceptibility to obesity. Am. J. Clin. Nutr. $\mathbf{8 7}$ 1606-1615 (2008).

129. Dupuis, J. et al. New genetic loci implicated in fasting glucose homeostasis and their impact on type 2 diabetes risk. Nat. Genet. 42, 105-116 (2010)

130. Barker, A. et al. Association of genetic Loci with glucose levels in childhood and adolescence: a meta-analysis of over 6,000 children. Diabetes 60 , 1805-1812 (2011)

131. Ruano, E. G., Canivell, S. \& Vieira, E. REV-ERB ALPHA polymorphism is associated with obesity in the Spanish obese male population. PLOS ONE 9. e104065 (2014).

132. Dashti, H. S. et al. Gene-environment interactions of circadian-related genes for cardiometabolic traits. Diabetes Care 38, 1456-1466 (2015).

133. Dashti, H. S. et al. CRY1 circadian gene variant interacts with carbohydrate intake for insulin resistance in two independent populations: Mediterranean and North American. Chronobiol. Int. 31, 660-667 (2014).

134. Garcia-Rios, A. et al. Beneficial effect of CLOCK gene polymorphism rs 1801260 in combination with low-fat diet on insulin metabolism in the patients with metabolic syndrome. Chronobiol. Int. 31, 401-408 (2014).

135. Garaulet, M. et al. CLOCK genetic variation and metabolic syndrome risk: modulation by monounsaturated fatty acids. Am. J. Clin. Nutr. 90 1466-1475 (2009).

136. Loria-Kohen, V. et al. Polymorphism in the CLOCK gene may influence the effect of fat intake reduction on weight loss. Nutrition 32, 453-460 (2016).

137. Corella, D. et al. CLOCK gene variation is associated with incidence of type-2 diabetes and cardiovascular diseases in type-2 diabetic subjects: dietary modulation in the PREDIMED randomized trial. Cardiovasc. Diabetol. 15, 4 (2016).

138. Ando, H. et al. Clock gene expression in peripheral leucocytes of patients with type 2 diabetes. Diabetologia 52, 329-335 (2009).

139. Otway, D. T. et al. Rhythmic diurnal gene expression in human adipose tissue from individuals who are lean, overweight, and type 2 diabetic. Diabetes 60 , 1577-1581 (2011) First study comparing in vivo clock gene expression rhythms between healthy participants, participants with obesity and patients with type 2 diabetes mellitus.

140. Wright, K. P. Jr. et al. Entrainment of the human circadian clock to the natural light-dark cycle. Curr. Biol. 23, 1554-1558 (2013).

141. Fonken, L. K. et al. Light at night increases body mass by shifting the time of food intake. Proc. Natl Acad. Sci. USA 107, 18664-18669 (2010).

142. Obayashi, K. et al. Exposure to light at night nocturnal urinary melatonin excretion, and obesity/ dyslipidemia in the elderly: a cross-sectional analysis of the HEIJO-KYO study. J. Clin. Endocrinol. Metab. 98, 337-344 (2013)

143. McFadden, E., Jones, M. E., Schoemaker, M. J., Ashworth, A. \& Swerdlow, A. J. The relationship between obesity and exposure to light at night: crosssectional analyses of over 100,000 women in the Breakthrough Generations study. Am. J. Epidemiol. 180, 245-250 (2014).

144. Obayashi, K., Saeki, K., Iwamoto, J., Ikada, Y. \& Kurumatani, N. Independent associations of exposure to evening light and nocturnal urinary melatonin excretion with diabetes in the elderly. Chronobiol. Int 31, 394-400 (2014).

145. Cheung, I. N. et al. Morning and evening blue-enriched light exposure alters metabolic function in normal weight adults. PLOS ONE 11, e0155601 (2016).

146. Albreiki, M. S., Middleton, B. \& Hampton, S. M. A single night light exposure acutely alters hormonal and metabolic responses in healthy participants. Endocr. Connect. 6, 100-110 (2017).

147. Versteeg, R. I. et al. Acute effects of morning light on plasma glucose and triglycerides in healthy men and men with type 2 diabetes. J. Biol. Rhythms 32, 130-142 (2017)

148. Opperhuizen, A. L. et al. Light at night acutely impairs glucose tolerance in a time-, intensity- and wavelengthdependent manner in rats. Diabetologia 60 1333-1343 (2017).

149. Lewy, A. J. \& Sack, R. L. The dim light melatonin onset as a marker for circadian phase position. Chronobiol. Int. 6, 93-102 (1989).

150. Rubio-Sastre, P., Scheer, F. A., Gomez-Abellan, P. Madrid, J. A. \& Garaulet, M. Acute melatonin administration in humans impairs glucose tolerance in both the morning and evening. Sleep 37, 1715-1719 (2014).

151. Cagnacci, A. et al. Influence of melatonin administration on glucose tolerance and insulin sensitivity of postmenopausal women. Clin. Endocrinol. (Oxf.) 54, 339-346 (2001).

152. Garaulet, M. et al. Common type 2 diabetes risk variant in MTNR1B worsens the deleterious effect of melatonin on glucose tolerance in humans. Metabolism 64, 1650-1657 (2015).

153. Bonnefond, A. \& Froguel, P. The case for too little melatonin signalling in increased diabetes risk. Diabetologia 60, 823-825 (2017).

154. McMullan, C. J., Schernhammer, E. S., Rimm, E. B. Hu, F. B. \& Forman, J. P. Melatonin secretion and the incidence of type 2 diabetes. JAMA 309, 1388-1396 (2013).

155. Bonnefond, A. et al. Rare MTNR1B variants impairing melatonin receptor $1 \mathrm{~B}$ function contribute to type 2 diabetes. Nat. Genet. 44, 297-301 (2012).

156. Shan, Z. et al. Sleep duration and risk of type 2 diabetes: a meta-analysis of prospective studies. Diabetes Care 38, 529-537 (2015). Meta-analysis demonstrating an association between sleep duration and the incidence of type 2 diabetes mellitus.

157. Stamatakis, K. A. \& Punjabi, N. M. Long sleep duration: a risk to health or a marker of risk? Sleep Med. Rev. 11, 337-339 (2007).

158. Cappuccio, F. P., D'Elia, L., Strazzullo, P. \& Miller, M. A Quantity and quality of sleep and incidence of type 2 diabetes: a systematic review and meta-analysis. Diabetes Care 33, 414-420 (2010).

159. Bosy-Westphal, A. et al. Influence of partial sleep deprivation on energy balance and insulin sensitivity in healthy women. Obes. Facts 1, 266-273 (2008).

160. Nedeltcheva, A. V. et al. Sleep curtailment is accompanied by increased intake of calories from snacks. Am. J. Clin. Nutr. 89, 126-133 (2009).

161. Reutrakul, S. \& Mokhlesi, B. Obstructive sleep apnea and diabetes: a state of the art review. Chest 152. 1070-1086 (2017).

162. Spiegel, K., Leproult, R. \& Van Cauter, E. Impact of sleep debt on metabolic and endocrine function. Lancet 354, 1435-1439 (1999). Seminal experimental study showing the detrimental effect of sleep debt on glucose metabolism.

163. Donga, E. et al. A single night of partial sleep deprivation induces insulin resistance in multiple metabolic pathways in healthy subjects. J. Clin. Endocrinol. Metab. 95, 2963-2968 (2010).

164. Broussard, J. L., Ehrmann, D. A., Van Cauter, E. Tasali, E. \& Brady, M. J. Impaired insulin signaling in human adipocytes after experimental sleep restriction: a randomized, crossover study. Ann. Intern. Med. 157, 549-557 (2012).

165. Buxton, O. M. et al. Sleep restriction for 1 week reduces insulin sensitivity in healthy men. Diabetes 59, 2126-2133 (2010)

166. Cedernaes, J. et al. A single night of partial sleep loss impairs fasting insulin sensitivity but does not affect cephalic phase insulin release in young men. J. Sleep Res. 25, 5-10 (2016)

167. Rao, M. N. et al. Subchronic sleep restriction causes tissue-specific insulin resistance. J. Clin. Endocrinol. Metab. 100, 1664-1671 (2015). 
168. van Leeuwen, W. M. et al. Prolonged sleep restriction affects glucose metabolism in healthy young men. Int. J. Endocrinol. 2010, 108641 (2010).

169. Robertson, M. D., Russell-Jones, D., Umpleby, A. M $\&$ Dijk, D. J. Effects of three weeks of mild sleep restriction implemented in the home environment on multiple metabolic and endocrine markers in healthy young men. Metabolism 62, 204-211 (2013).

170. St-Onge, M. P., O'Keeffe, M., Roberts, A. L. RoyChoudhury, A. \& Laferrere, B. Short sleep duration, glucose dysregulation and hormonal regulation of appetite in men and women. Sleep 35 1503-1510 (2012)

171. Tasali, E., Leproult, R., Ehrmann, D. A. \& Van Cauter, E. Slow-wave sleep and the risk of type 2 diabetes in humans. Proc. Natl Acad. Sci. USA 105, 1044-1049 (2008).

172. Stamatakis, K. A. \& Punjabi, N. M. Effects of sleep fragmentation on glucose metabolism in normal subjects. Chest 137, 95-101 (2010).

173. Herzog, N. et al. Selective slow wave sleep but not rapid eye movement sleep suppression impairs morning glucose tolerance in healthy men. Psychoneuroendocrinology 38, 2075-2082 (2013).

174. Lee, S. W. H., Ng, K. Y. \& Chin, W. K. The impact of sleep amount and sleep quality on glycemic control in type 2 diabetes: A systematic review and metaanalysis. Sleep Med. Rev. 31, 91-101 (2017). Systematic review showing the relationship between sleep and glycaemic control in patients with type 2 diabetes mellitus.

175. Merikanto, I. et al. Associations of chronotype and sleep with cardiovascular diseases and type 2 diabetes. Chronobiol. Int. 30, 470-477 (2013).

176. Yu, J. H. et al. Evening chronotype is associated with metabolic disorders and body composition in middle-aged adults. J. Clin. Endocrinol. Metab. 100 1494-1502 (2015)

177. Vetter, C. et al. Mismatch of sleep and work timing and risk of type 2 diabetes. Diabetes Care 38 , 1707-1713 (2015).

\section{Study demonstrating the association between social} jet lag and the risk of type 2 diabetes mellitus.

178. Parsons, M. J. et al. Social jetlag, obesity and metabolic disorder: investigation in a cohort study. Int. J. Obes. 39, 842-848 (2015)

179. Koopman, A. D. M. et al. The association between social jetlag, the metabolic syndrome, and type 2 diabetes mellitus in the general population: the New Hoorn study. J. Biol. Rhythms 32, 359-368 (2017)

180. Reutrakul, S. et al. Chronotype is independently associated with glycemic control in type 2 diabetes. Diabetes Care 36, 2523-2529 (2013).

181. Osonoi, Y. et al. Morningness-eveningness questionnaire score and metabolic parameters in patients with type 2 diabetes mellitus. Chronobiol. Int 31, 1017-1023 (2014).

182. Gan, Y. et al. Shift work and diabetes mellitus: a metaanalysis of observational studies. Occupat. Environ. Med. 72, 72-78 (2015)

Meta-analysis showing the association between shift work and diabetes mellitus.

183. Vetter, C. et al. Night shift work, genetic risk, and type 2 diabetes in the UK biobank. Diabetes Care $\mathbf{4 1}$, 762-769 (2018)

184. Leproult, R., Holmback, U. \& Van Cauter, E. Circadian misalignment augments markers of insulin resistance and inflammation, independently of sleep loss. Diabetes 63, 1860-1869 (2014)

185. Qian, J., Dalla Man, C., Morris, C. J., Cobelli, C. \& Scheer, F. A. Differential effects of the circadian system and circadian misalignment on insulin sensitivity and insulin secretion in humans. Diabetes Obes. Metab. 20, 2481-2485 (2018)

186. Wefers, J. et al. Circadian misalignment induces fatty acid metabolism gene profiles and compromises insulin sensitivity in human skeletal muscle. Proc. Natl Acad. Sci. USA 115, 7789-7794 (2018).

187. Opperhuizen, A. L., van Kerkhof, L. W., Proper, K. I., Rodenburg, W. \& Kalsbeek, A. Rodent models to study the metabolic effects of shiftwork in humans. Front. Pharmacol. 6, 50 (2015)

188. Thaiss, C. A. et al. Transkingdom control of microbiota diurnal oscillations promotes metabolic homeostasis. Cell 159, 514-529 (2014)

189. Riemersma-van der Lek, R. F. et al. Effect of bright light and melatonin on cognitive and noncognitive function in elderly residents of group care facilities: a randomized controlled trial. JAMA 299. 2642-2655 (2008)

190. Hu, K. et al. Progression of dementia assessed by temporal correlations of physical activity: results from a 3.5-Year, longitudinal randomized controlled trial. Sci. Rep. 6, 27742 (2016)

191. Sander, B., Markvart, J., Kessel, L., Argyraki, A. \& Johnsen, K. Can sleep quality and wellbeing be improved by changing the indoor lighting in the homes of healthy, elderly citizens? Chronobiol. Int. 32 1049-1060 (2015).

192. Chang, A.-M., Aeschbach, D., Duffy, J. F. \& Czeisler, C. A Evening use of light-emitting eReaders negatively affects sleep, circadian timing, and next-morning alertness. Proc. Natl Acad. Sci. 112, 1232-1237 (2015)

193. Tan, X., van Egmond, L., Chapman, C. D., Cedernaes, J. $\&$ Benedict, C. Aiding sleep in type 2 diabetes: therapeutic considerations. Lancet Diabetes Endocrinol. 6, 60-68 (2018).

194. Young, T. Increasing sleep duration for a healthier (and less obese?) population tomorrow. Sleep 31 593-594 (2008).

195. Leproult, R., Deliens, G., Gilson, M. \& Peigneux, P. Beneficial impact of sleep extension on fasting insulin sensitivity in adults with habitual sleep restriction. Sleep 38, 707-715 (2015).

196. Cizza, G., Piaggi, P., Rother K. I \& Csako, G. \& Sleep Extension Study, G. Hawthorne effect with transient behavioral and biochemical changes in a randomized controlled sleep extension trial of chronically short-sleeping obese adults: implications for the design and interpretation of clinical studies. PLOS ONE 9, e104176 (2014)

197. Riemann, D. et al. European guideline for the diagnosis and treatment of insomnia. J. Sleep Res. 26, 675-700 (2017).

198. Chen, L. et al. Continuous positive airway pressure and diabetes risk in sleep apnea patients: a system review and meta-analysis. Eur. J. Intern. Med. 39 39-50 (2017)

\section{Meta-analysis investigating a potential relation} between obstructive sleep apnoea treatment and the risk of developing type 2 diabetes mellitus

199. Zhu, B., Ma, C., Chaiard, J. \& Shi, C. Effect of continuous positive airway pressure on glucose metabolism in adults with type 2 diabetes: a systematic review and meta-analysis of randomized controlled trials. Sleep Breath. 22, 287-295 (2017).

200. Martinez-Ceron, E. et al. Effect of continuous positive airway pressure on glycemic control in patients with obstructive sleep apnea and type 2 diabetes. A randomized clinical trial. Am. J. Respir. Crit. Care Med. 194, 476-485 (2016).

201. Mokhlesi, B., Grimaldi, D., Beccuti, G. \& Van Cauter, E. Effect of one week of CPAP treatment of obstructive sleep apnoea on 24-hour profiles of glucose, insulin and counter-regulatory hormones in type 2 diabetes. Diabetes Obes. Metab. 19, 452-456 (2017).

202. Colberg, S. R. et al. Physical activity/exercise and diabetes: a position statement of the American Diabetes Association. Diabetes Care 39, 2065-2079 (2016).

203. Buxton O. M., Lee, C. W. L'Hermite-Baleriaux, M. Turek, F. W. \& Van Cauter, E. Exercise elicits phase shifts and acute alterations of melatonin that vary with circadian phase. Am. J. Physiol. Regul. Integr. Comp. Physiol. 284, R714-R724 (2003).

204. Kredlow, M. A. Capozzoli, M. C., Hearon, B. A Calkins, A. W. $\&$ Otto, M. W. The effects of physical activity on sleep: a meta-analytic review. J. Behav. Med. 38, 427-449 (2015).

205. Mattson, M. P et al. Meal frequency and timing in health and disease. Proc. Natl Acad. Sci. USA 111. 16647-16653 (2014).

206. St-Onge, M. P. et al. Meal timing and frequency: implications for cardiovascular disease prevention: a scientific statement from the American Heart Association. Circulation 135, e96-e121 (2017). Statement from the American Heart Association on the effects of meal timing and frequency for metabolic health

207. Jakubowicz, D., Barnea, M., Wainstein, J. \& Froy, O. High caloric intake at breakfast versus dinner differentially influences weight loss of overweight and obese women. Obesity 21, 2504-2512 (2013).

208. Farshchi, H. R., Taylor, M. A. \& Macdonald, I. A Beneficial metabolic effects of regular meal frequency on dietary thermogenesis, insulin sensitivity, and fasting lipid profiles in healthy obese women. $\mathrm{Am}$. J. Clin. Nutr. 81, 16-24 (2005)

209. Farshchi, H. R., Taylor, M. A. \& Macdonald, I. A. Deleterious effects of omitting breakfast on insulin sensitivity and fasting lipid profiles in healthy lean women. Am. J. Clin. Nutr. 81, 388-396 (2005)

210. Chowdhury, E. A. et al. The causal role of breakfast in energy balance and health: a randomized controlled trial in obese adults. Am. J. Clin. Nutr. 103, 747-756 (2016).
211. Betts, J. A. et al. The causal role of breakfast in energy balance and health: a randomized controlled trial in lean adults. Am. J. Clin. Nutr. 100, 539-547 (2014)

212. Versteeg, R. I. et al. Meal timing effects on insulin sensitivity and intrahepatic triglycerides during weight loss. Int J Obes. 42, 156-162 (2017).

213. Gill, S. \& Panda, S. A. Smartphone app reveals erratic diurnal eating patterns in humans that can be modulated for health benefits. Cell Metab. 22 789-798 (2015).

Study demonstrating chaotic diurnal eating patterns in humans, as well as the potential clinical benefits of time-restricted feeding.

214. Sutton, E. F. et al. Early time-restricted feeding improves insulin sensitivity, blood pressure, and oxidative stress even without weight loss in men with prediabetes. Cell Metab. 27, 1212-1221 (2018).

215. Holman, R. R., Sourij, H. \& Califf, R. M. Cardiovascular outcome trials of glucose-lowering drugs or strategies in type 2 diabetes. Lancet 383, 2008-2017 (2014).

216. Um, J. H. et al. Activation of 5'-AMP-activated kinase with diabetes drug metformin induces casein kinase lepsilon (CKlepsilon)-dependent degradation of clock protein mPer2. J. Biol. Chem. 282, 20794-20798 (2007).

217. Barnea, M. et al. Metformin affects the circadian clock and metabolic rhythms in a tissue-specific manner. Biochim. Biophys. Acta 1822, 1796-1806 (2012).

218. Henriksson, E. et al. The liver circadian clock modulates biochemical and physiological responses to metformin. J. Biol. Rhythms 32, 345-358 (2017).

219. Baker, I. A. \& Jarrett, R. J. Diurnal variation in the blood-sugar and plasma-insulin response to tolbutamide. Lancet 2, 945-947 (1972).

220. Webb, I. C., Lehman, M. N. \& Coolen, L. M. Diurnal and circadian regulation of reward-related neurophysiology and behavior. Physiol. Behav. 143 58-69 (2015)

221. Ter Horst, K. W. et al. Striatal dopamine regulates systemic glucose metabolism in humans and mice. Sci. Transl Med. 10, eaar3752 (2018).

222. Liang, W. et al. Efficacy and safety of bromocriptineQR in type 2 diabetes: a systematic review and metaanalysis. Horm. Metab. Res. 47, 805-812 (2015).

223. Garfinkel, D. et al. Efficacy and safety of prolongedrelease melatonin in insomnia patients with diabetes: a randomized, double-blind, crossover study. Diabetes Metab. Syndr. Obes. 4, 307-313 (2011).

224. Holleman, F. \& Gale, E. A. Nice insulins, pity about the evidence. Diabetologia 50, 1783-1790 (2007).

225. Wallia, A. \& Molitch, M. E. Insulin therapy for type 2 diabetes mellitus. JAMA 311, 2315-2325 (2014).

226. Stenvers, D. J., DeVries, J. H. \& la Fleur, S. E. What's the time? Does the artificial pancreas need to know? Diabetes 62, 2173-2174 (2013).

227. Thabit, H. et al. Closed-loop insulin delivery in inpatients with type 2 diabetes: a randomised, parallel-group trial. Lancet Diabetes Endocrinol. 5, 117-124 (2016)

228. Johannsson, G. et al. Improved cortisol exposure-time profile and outcome in patients with adrenal insufficiency: a prospective randomized trial of a novel hydrocortisone dual-release formulation. J. Clin. Endocrinol. Metab. 97, 473-481 (2012).

229. Quinkler, M., Miodini Nilsen, R., Zopf, K., Ventz, M. \& Oksnes, M. Modified-release hydrocortisone decreases $\mathrm{BMI}$ and $\mathrm{HbA} 1 \mathrm{c}$ in patients with primary and secondary adrenal insufficiency. Eur. J. Endocrinol. 172, 619-626 (2015)

230. Giordano, R. et al. Improvement of anthropometric and metabolic parameters, and quality of life following treatment with dual-release hydrocortisone in patients with Addison's disease. Endocr 51, 360-368 (2016)

231. Zhang, E. E. et al. A genome-wide RNAi screen for modifiers of the circadian clock in human cells. Cell 139, 199-210 (2009)

232. Chen, Z. et al. Identification of diverse modulators of central and peripheral circadian clocks by highthroughput chemical screening. Proc. Natl Acad. Sci. USA 109, 101-106 (2012).

233. Chen, Z., Yoo, S. H. \& Takahashi, J. S. Development and therapeutic potential of small-molecule modulators of circadian systems. Annu. Rev. Pharmacol. Toxicol. 58, 231-252 (2018).

234. Solt, L. A. et al. Regulation of circadian behaviour and metabolism by synthetic REV-ERB agonists. Nature 485, 62-68 (2012). Study demonstrating beneficial metabolic effects of targeting the molecular clock with REV-ERB agonists in mice. 
235. He, B. et al. The small molecule nobiletin targets the molecular oscillator to enhance circadian rhythms and protect against metabolic syndrome. Cell Metab. 23, 610-621 (2016)

Study demonstrating that nobiletin improves

metabolic health in mouse models of the metabolic syndrome by strengthening the molecular clock.

236. Humphries, P. S. et al. Carbazole-containing sulfonamides and sulfamides: discovery of cryptochrome modulators as antidiabetic agents. Bioorg. Med. Chem Lett. 26, 757-760 (2016).

237. Humphries, P. S. et al. Carbazole-containing amides and ureas: discovery of cryptochrome modulators as antihyperglycemic agents. Bioorg. Med. Chem. Lett. 28, 293-297 (2017)
238. Laing, E. E. et al. Blood transcriptome based biomarkers for human circadian phase. eLife 6 e20214 (2017)

239. Woller, A., Duez, H., Staels, B. \& Lefranc, M. A Mathematical model of the liver circadian clock linking feeding and fasting cycles to clock function. Cell Rep. 17, 1087-1097 (2016)

240. Samuel, V. T. \& Shulman, G. I. The pathogenesis of insulin resistance: integrating signaling pathways and substrate flux. J. Clin. Invest. 126, 12-22 (2016).

241. Wallace, T. M., Levy, J. C. \& Matthews, D. R. Use and abuse of HOMA modeling. Diabetes Care 27 1487-1495 (2004).

242. Sperling, L. S. et al. The CardioMetabolic Health Alliance: working toward a new care model for the metabolic syndrome. J. Am. College Cardiol. 66 . 1050-1067 (2015).
Author contributions

D.J.S. researched data for article, all authors provided a substantial contribution to discussion of content and wrote the article, F.A.J.L.S., P.S., S.E.L.F. and A.K. reviewed and edited the manuscript before submission.

\section{Competing interests}

F.A.J.L.S. received speaker fees from Bayer Healthcare, Kellogg Company, Philips, Pfizer, Sentara Healthcare and Vanda Pharmaceuticals. F.A.J.L.S. was supported in part by NIH grants R01DK099512, R01 HL118601, R01DK102696, R01DK 105072 and R01HL140574. The other authors declare no competing interests.

Publisher's note

Springer Nature remains neutral with regard to jurisdictional claims in published maps and institutional affiliations. 